Research Article

\title{
Modelling and Assessing the Performance of Hybrid PV-CSP Plants in Morocco: A Parametric Study
}

\author{
Loubna Bousselamti $(\mathbb{D})$ and Mohamed Cherkaoui \\ Engineering for Smart and Sustainable System Research Center, Mohammadia School of Engineers, Mohammed V University, \\ Rabat 10999, Morocco \\ Correspondence should be addressed to Loubna Bousselamti; loubnabousselamti@research.emi.ac.ma
}

Received 27 March 2019; Revised 29 June 2019; Accepted 3 September 2019; Published 16 October 2019

Academic Editor: Huiqing Wen

Copyright (c) 2019 Loubna Bousselamti and Mohamed Cherkaoui. This is an open access article distributed under the Creative Commons Attribution License, which permits unrestricted use, distribution, and reproduction in any medium, provided the original work is properly cited.

\begin{abstract}
Based on the examination of the efficiency of solar plants, this study focuses on three main plants: a photovoltaic (PV) plant, a concentrated solar power (CSP) plant, and a hybrid PV/CSP plant. The modelling of the three plants has been implemented to evaluate the influence of design parameters (orientation angles, solar multiple (SM), thermal energy storage capacity (TES), and fraction of hybridization) on them. Several simulations have been recreated and discussed in details to study the optimal configuration of the two first plants and the profitability of the PV/CSP plants for Ouarzazate (Morocco) location. The findings demonstrate that the optimal orientation angles and TES/SM, respectively, affect the performances of PV and CSP plants, and they also reveal that PV/CSP systems have the benefits to increase the annual energy produced, reduce the cost, and offer a high dispatchability to supply a baseload. The implementing of optimal PV/CSP plant has a great economic impact on Ouarzazate city.
\end{abstract}

\section{Introduction}

Climate change and shortage of natural resources for power production combined with the high increase of energy demand are posing a challenging scenario for the future energy supply [1]. In this context, nations worldwide have to seek for clean and efficient techniques to cover their energy demands for the years to come. It has been estimated that the potential of different renewable energy sources (RES) is enormous and will be sufficient to cover an important share on the future mixed electrical energy [2]. Each year, the solar radiation that reach the Earth's surface is approximately 885 million TWh [3]. The abundance of solar energy makes it a promising source for the production of clean energy [4]. Actually, the focus is to transform this source of energy efficiently in order to take full advantage of its benefits. The conversion of solar energy into electricity involves using two types of solar energy processes: photovoltaic (PV) and concentrating solar power (CSP) [1]. Today, they have reached different levels of growth and penetration. The PV technology has a highest commercial level than the CSP technology which is in rapid maturation [5].
PV converts solar energy directly into electricity through the photovoltaic effect and is now mature with a global installed capacity of around $303 \mathrm{GW}$ in 2016; it leaps to $402 \mathrm{GW}$ in 2017 and continues to increase strongly [5]. During the last years, the price of full PV equipment has been dropped. This has significantly reduced the PV levelized cost of electricity (LCOE) (about $6 \$ \mathrm{ct} / \mathrm{kWh}$ ) [6]. PV has stood as a feasible solution to supply electricity for buildings in remote and urban areas with or without connection to the grid [7]. Although, this, the absence of a cheap storage system, still makes large scale grid integration of electricity from PV troublesome due to intermittency and unpredictability of the solar energy. Storage may add an additional option of dispatchability, but actually, it is too costly to be implemented at a large scale.

On the other side, CSP uses a thermodynamic cycle process to generate mechanical energy in a turbine and then uses a generator for the conversion of this mechanical energy to electrical energy. CSP deployment has experienced growth in the latter years, with a global installed capacity of around $4.9 \mathrm{GW}$ at the end of 2017 [5] and shall leap to $261 \mathrm{GW}$ by 2030 [8]. CSP has less installed capacity worldwide due to 
the added complexity and the high investment of its systems

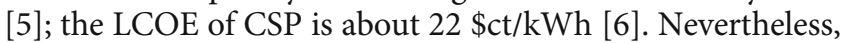
the strength of CSP over other renewable energy (RE) technologies is being dispatchable at a large scale by integrating of thermal storage. CSP plants associated with the thermal storage are a feasible solution to cover a baseload demand and supply the electricity during times of peak demand after daylight, when electricity prices are generally high. Thermal storage has made the CSP a very interesting technology for future renewable energy production $[9,10]$.

Within this context, PV and CSP may be perceived as competitors, but they proved to be complementary [1]. The idea of solution is to implement the two technologies in a single system in order to get a PV-CSP hybrid system to respond efficiently to a given need and increase the penetration of solar energy into the mixed electricity supply [11]. The hybrid PV-CSP system that combines the production of a low cost from the PV and dispatchable production from CSP results in a potentially more cost-effective production system compared to the two technologies alone $[12,13]$.

Several studies show the high efficiency of a hybrid PV-CSP system; Platzer [14] combines the 50MW CSP system (parabolic trough) with $12 \mathrm{~h}$ storage with $75 \mathrm{MW}$ concentrating photovoltaic plant (CPV) to increase the operation duration of the hybrid plant; in another study [15], he combines CSP (Fresnel molten salt power plant) and CPV, which permits to reach a high capacity factor and simultaneously a lower LCOE than for a CSP power plant alone. A similar concept [11] has been implemented by combining $100 \mathrm{MW}$ CSP tower plant with $100 \mathrm{MW}$ PV plant to supply $100 \mathrm{MW}$ baseload capacity to the South-African electricity grid. In another study, the hybrid PV-CSP plant proves that it is possible to make a continuous production of electricity to supply intermediate and peak load [16]. For both locations of Ouarzazate (Morocco) and of Ottana (Italy), the hybridization of a PV plant and a CSP plant based on Fresnel collector with organic Rankine cycle (ORC) is highly and effectively costed [17]. Parrado et al. [18] calculates the LCOE until 2050 for $50 \mathrm{MW}$ power plants: a PV plant, a CSP plant with $15 \mathrm{~h}$ TES, and a hybrid PV-CSP plant; the PV-CSP hybrid plant generates a continuous production to satisfy electricity demand with a reduced cost. Regarding dispatching strategy of a PV-CSP system, Zhai et al. [19] proposes a technoeconomic analysis of a PV-CSP system in two dispatch strategies; the strategy that prioritizes the use of $\mathrm{PV}$ during the day and CSP during the night is more profitable than the strategy that operates PV and CSP independently. All studies confirm that the use of a PV-CSP system associated with thermal storage may achieve a high capacity factor and can provide more economical production in a long time comparing with a PV or a CSP plant, for all location of studies [19-21].

Various commercial PV-CSP hybrid projects are actually under development or under construction. In Chile's desert, Abengoa launched the Atacama 1 and 2 in 2013 and 2015, respectively. The two plants based on a $100 \mathrm{MW}$ PV plant and a $110 \mathrm{MW}$ tower plant with a $17.5 \mathrm{~h}$ molten salt thermal storage capacity for Atacama I and a $15 \mathrm{~h}$ molten salt thermal storage capacity for Atacama II [8, 22]. SolarReserve develops another PV-CSP plant in Chile's desert called Copiapo; the plant incorporates a $150 \mathrm{MW}$ PV plant and a $130 \mathrm{MW}$ CSP tower plant with a $14 \mathrm{~h}$ molten salt storage capacity. In South Africa, the union of the $100 \mathrm{MW}$ Redstone CSP plant with the $96 \mathrm{MW}$ Jasper and the $75 \mathrm{MW}$ Lesedi PV plants is planned to be realized to form the world's first hybrid PV-CSP plant with a global capacity of $271 \mathrm{MW}$ [8].

In this framework, the aim of this paper is to evaluate the design parameters (orientation angles, solar multiple, TES capacity, and the fraction of hybridization) on a PV plant, a CSP plant, and a PV/CSP plant and assess the benefits and drawbacks of a hybrid PV-CSP power plant through a parametric study in order to supply a baseload capacity. The study has been investigated for Ouarzazate (Morocco).

\section{System Modelling}

2.1. Solar Resource. For a reliable assessment of CSP and PV plants, meteorological data at close intervals of time throughout a typical meteorological year (TMY) are required. The TMY file includes hourly data of direct normal irradiance (DNI), diffuse horizontal irradiance (DHI), global horizontal irradiance $(\mathrm{GHI})$, ambient temperature $(\mathrm{T})$, and wind velocity (v) [23]. Morocco has a higher potential of direct and global solar radiation of about $2500 \mathrm{kWh} / \mathrm{m}^{2} /$ year and $2200 \mathrm{kWh} / \mathrm{m}^{2} /$ year, respectively, in the southern region [24, $25]$. For this reason, Ouarzazate $\left(30^{\circ} 55^{\prime} 08^{\prime \prime} \mathrm{N}, 6^{\circ} 53^{\prime} 36^{\prime \prime} \mathrm{E}\right)$ which is located in the south of Morocco and receives a high solar radiation is chosen for this study.

Figure 1(a) illustrates a comparison between the monthly values of average GHI and DNI. Ouarzazate has a high value of daily GHI between April and August and a high value of DNI between January and June; the minimal value of daily GHI and DNI is $3.5 \mathrm{kWh} / \mathrm{m}^{2}$ and $6 \mathrm{kWh} / \mathrm{m}^{2}$, respectively. The low limit value of annual DNI for a CSP plant to achieve economic performance is generally set between $1900 \mathrm{Wh} / \mathrm{m}^{2}$ and $2000 \mathrm{Wh} / \mathrm{m}^{2}$; the DNI is the highest potential in arid areas like Ouarzazate. That is to say, it is an optimal location for the placement of CSP plants [26]. Figure 1(b) illustrates the annual averaged hourly profile of GHI, DNI, and temperature; it can explain the favorable solar radiation in Ouarzazate. The GHI has its peak at noon, the DNI is higher throughout the day, and the average temperature does not exceed $25^{\circ} \mathrm{C}$ which is an advantage for a PV and a CSP plant. The availability of solar radiation highly influences the performance of PV and CSP plants and leads to greater efficiency for the solar plants in Ouarzazate.

2.2. PV Model. The PV model is a mathematical representation to estimate the energy production of a PV system. The model proposed based on empirical relationships simplified via different assumptions regarding system components and losses factors with the aim of reaching closer simulation to reality results.

The global radiation estimation can be done at the hourly, daily, or monthly scale; many models have been developed based on the following viewpoint. The hourly estimate of solar radiation is the most accurate method because it has recorded the detailed changes of solar radiation in a day. 


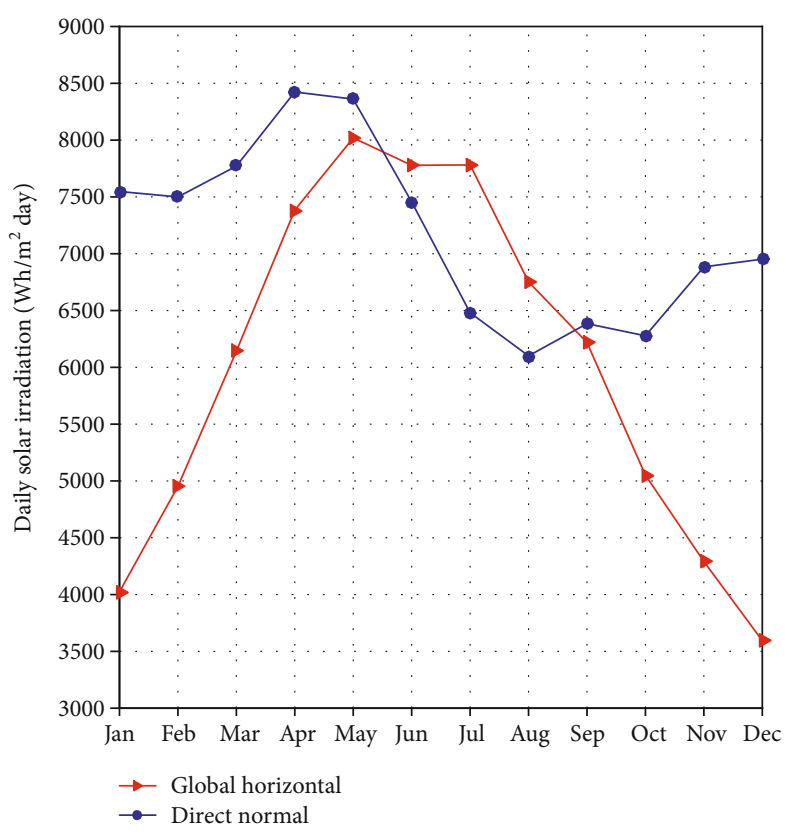

(a)

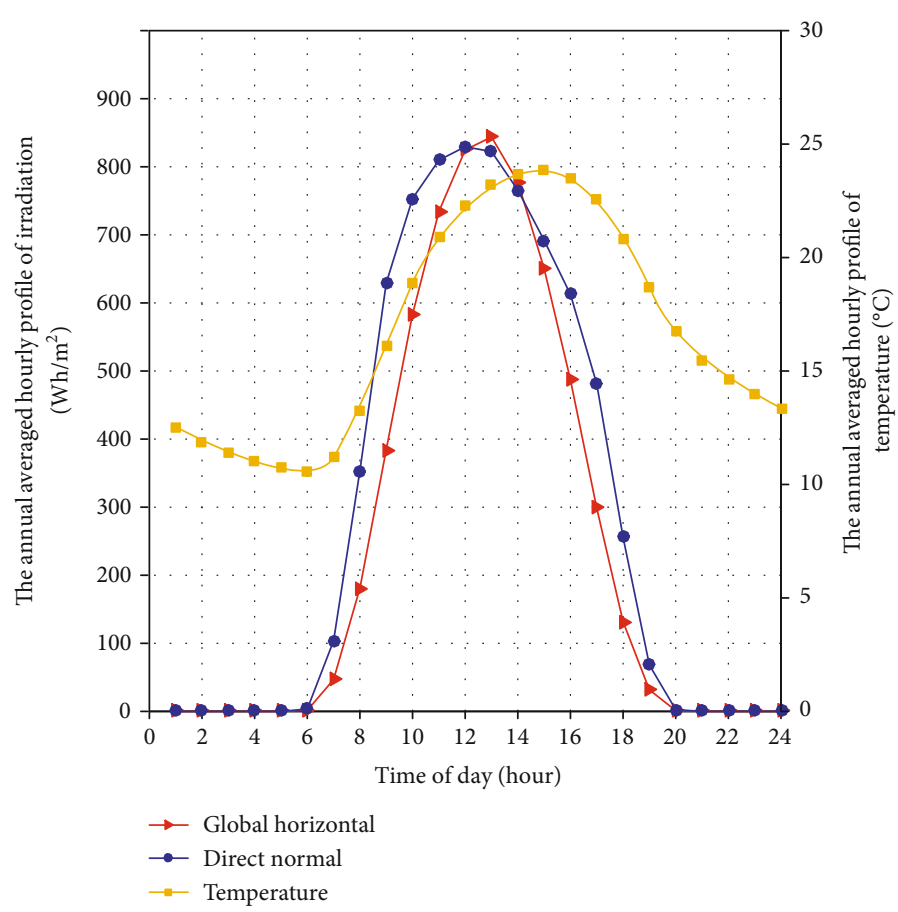

(b)

FIgURE 1: (a) Monthly average values of global and direct irradiation for Ouarzazate. (b) The annual averaged hourly global horizontal irradiation, direct normal irradiation, and temperature profile for Ouarzazate.

The global solar irradiation on inclined surface $G_{i}$ is the sum of the beam normal irradiation $B_{n}$, diffused irradiation $D_{i}$, and reflected irradiation $I_{r}$, intercepted by the surface during a time interval.

It is calculated using equation (1), which also accounts for the angle of incidence $\theta$ [27].

$$
G_{i}=B_{n} \cos \theta+D_{i}+I_{r}
$$

The component of the reflected irradiation is calculated by equation (2), by introducing the notion of albedo $\rho$, which is the ratio of the incident radiation reflected on the incident radiation [28].

$$
I_{r}=\frac{1-\cos i}{2} \rho G_{h}
$$

where $G_{h}$ is the global horizontal irradiation and $i$ is the tilt angle of a PV panel.

Several models are developed to calculate the inclined diffused solar irradiation $D_{i}$. Our model proposed that the diffused irradiation is calculated using the HDKR model [29] also used in SAM software [28], and according to the literature, it is among the most cited models [30].

The angle of incidence $\theta$ is extracted from the relationship between the orientation of module ( $i$ is the tilt angle, $\gamma$ $s$ is the azimuth surface) and the sun's position for a given location ( $\alpha$ is the solar altitude angle, $\gamma$ is the solar azimuth angle); it can be calculated using equation (3) [29].

$$
\cos \theta=\operatorname{Sin} \alpha \operatorname{Cos} i-\operatorname{Cos} \alpha \operatorname{Cos}(\gamma-\gamma s) \operatorname{Sin} i .
$$

The power produced by a PV module is strongly affected by the geographic location of the system, solar radiation, PV material, PV module orientation, aging, and cell temperature. Hence, to calculate it, the cell temperature $T_{c}$ and module efficiency $\eta_{\mathrm{PV}}$ must be estimated firstly using equations (4) and (5), respectively [31].

$$
T_{c}=T_{\mathrm{amb}}+G_{i} e^{a+b \cdot v}+G_{i}\left(\frac{\Delta T}{1000}\right),
$$

where $T_{\mathrm{amb}}$ is the ambient temperature, $v$ is the wind velocity, and $\mathrm{a}, \mathrm{b}$, and $\Delta T$ are parameters that characterize the module.

$$
\eta_{\mathrm{PV}}=\eta_{\mathrm{ref}}\left(1-\gamma\left(T_{c}-T_{\mathrm{ref}}\right)\right)
$$

where $\eta_{\text {ref }}$ is the PV module nominal efficiency, $\gamma$ is the temperature factor, and $T_{\text {ref }}$ is the PV module temperature under standard test conditions.

The output energy of a PV system can be calculated by equation (6) [17]:

$$
P_{\mathrm{PV}}=G_{i} N_{\text {module }} A_{\mathrm{PV}} \eta_{\mathrm{PV}} \eta_{\text {inv }} f_{\mathrm{PV}},
$$

where $N_{\text {module }}$ is the number of PV modules according to the installed power, $A_{\mathrm{PV}}$ is the area of each PV module, $\eta_{\text {inv }}$ is the inverter efficiency, and $f_{\mathrm{PV}}$ is the factor losses considered to account for some losses such us soiling of the panels, wiring losses, shading, and other secondary losses.

2.3. CSP Model. A CSP power plant concentrates the direct radiation using mirrors/reflectors in order to heat a heat 
transfer fluid. The heat is used to create steam to drive a turbine to generate electricity production. Four optical types of CSP technologies exist, namely, parabolic trough, solar power tower, dish sterling, and linear reflector Fresnel. Parabolic trough is the technology selected in this study due to its great maturity and industrial development [33]. The parabolic trough power generation model mainly consists of a solar field (SF), a system of TES, and a power block (PB). Solar field is composed of a certain number of collectors, reflecting incident solar energy onto its focal line toward a receiver. The reflected solar power is calculated as equation (7) [34].

$$
Q_{\text {field }}=B_{n} \cos \theta_{i} A_{\text {field }} \text {, }
$$

where $\theta_{i}$ is the angle of incidence of collector and $A_{\text {field }}$ is the effective aperture area.

The absorbed power by the receiver tubes can be written as equation $(8)[23,34]$.

$$
Q_{\text {receiver }}=Q_{\text {field }} \eta_{\text {col }} \eta_{\text {rec }} k_{\theta} \eta_{\text {shadow }} \eta_{\text {end-losses }} \eta_{\text {track }}
$$

where $\eta_{\text {col }}$ is the optical efficiency, $\eta_{\text {rec }}$ is the nominal receiver efficiency, $k_{\theta}$ is the incidence angle modifier [34], $\eta_{\text {shadow }}$ is the row shadowing factor [34], $\eta_{\text {end-losses }}$ is the end losses factor [35], and $\eta_{\text {track }}$ is the solar collector field tracking factor [35].

The net power collected by the heat transfer fluid over the field is the difference between the absorbed power by the receiver and the sum of heat loss from the receivers $Q_{\text {receiver_losses }}$ and heat loss from the piping $Q_{\text {pipe_losses }}$ as shown in equation (9) [1].

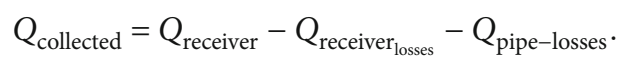

The hourly operating characteristic analysis of the CSP system is based on the meteorological and geographical conditions, especially solar radiation and location.

2.4. Levelized Cost of Energy. According to the literature, the LCOE is a decision support tool for investors. It is used to justify the choice of installation types and installation locations. The LCOE of a technology is obtained by dividing the total life cycle cost of the project by the total energy generated by the facility over the life of the project as shown in equation (10) [36].

$$
\mathrm{LCOE}=\frac{I_{\mathrm{inv}}+\sum_{t=1}^{T}\left(A_{\text {cost }} /(1+a)^{t}\right)}{\sum_{t=1}^{T}\left(\left(E_{\text {annual }}(1-d)^{t}\right) /(1+a)^{t}\right)},
$$

where $I_{\text {inv }}$ is the investment initial cost, $A_{\text {cost }}$ is the annual cost of the plant, $E_{\text {annual }}$ is the first year energy generation, $d$ is the annual degradation factor for a system, $a$ is the discount rate, and $T$ is the plant lifetime.

The investment initial cost of the plant includes direct and indirect component costs. For the CSP plant, the direct cost associated the cost of solar field, power bloc, piping system, storage system, HTF fluid, and balance of plant. For the $\mathrm{PV}$ plant, the direct cost associated the cost of PV modules,
TABLE 1: Financial parameters for PV and CSP plants [32].

\begin{tabular}{lcc}
\hline Parameter & Value & Unit \\
\hline PV cost & & \\
Solar modules & 0.45 & $\$ / \mathrm{W}$ \\
Inverters & 0.13 & $\$ / \mathrm{W}$ \\
Labour cost & 0.15 & $\$ / \mathrm{W}$ \\
Balance of system equipment & 0.10 & $\$ / \mathrm{W}$ \\
Installer margin and overhead & 0.22 & $\$ / \mathrm{W}$ \\
Annual operational and maintenance cost & 10 & $\$ / \mathrm{kW} / \mathrm{year}$ \\
Real interest rate & 5 & $\%$ \\
Degradation factor & 1 & $\% / \mathrm{year}$ \\
Lifetime & 25 & Years \\
CSP cost & & \\
Solar field & 120 & $\$ / \mathrm{m}^{2}$ \\
Heat transfer fluid & 50 & $\$ / \mathrm{m}^{2}$ \\
Power bloc & 1050 & $\$ / \mathrm{kWh}_{\mathrm{el}}$ \\
Thermal energy storage system & 60 & $\$ / \mathrm{kWh}_{\mathrm{th}}$ \\
EPC and owner cost & 11 & $\%$ \\
Balance of plant & 110 & $\$ / \mathrm{kWh}_{\mathrm{el}}$ \\
Contingency & 2 & $\$ / \mathrm{kWh}_{\mathrm{el}}$ \\
O\&M cost & 20 & $\$ / \mathrm{MWh}_{\mathrm{el}}$ \\
Real interest rate & 5 & $\%$ \\
Degradation rate & 0.2 & $\% / \mathrm{year}$ \\
Lifetime & 25 & Years \\
\hline
\end{tabular}

inverters, and balance of plant. For both plants, the indirect cost is calculated including procurement, engineering, and construction costs. The PV and CSP annual costs include operation, maintenance, and insurance costs.

In order to hybrid PV and CSP, the LCOE of the PVCSP system is calculated using equation (11) that includes the annual generation $\left(E_{\mathrm{PV}}, E_{\mathrm{CSP}}\right)$ and $\mathrm{LCOE}\left(\mathrm{LCOE}_{\mathrm{PV}}\right.$, $\mathrm{LCOE}_{\mathrm{CSP}}$ ) from PV and CSP plants [37].

$$
\mathrm{LCOE}_{\mathrm{PV}-\mathrm{CSP}}=\frac{\mathrm{LCOE}_{\mathrm{PV}} E_{\mathrm{PV}}+\mathrm{LCOE}_{\mathrm{CSP}} E_{\mathrm{CSP}}}{E_{\mathrm{PV}}+E_{\mathrm{CSP}}} .
$$

The cost estimation and financial parameters for simulation are presented in Table 1 for PV and CSP plants. For our simulation, the LCOE calculation of PV and CSP plants does not include the cost of the site.

\section{Result and Discussion}

3.1. Validation of Model. The PV and CSP models discussed in the previous sections are established according to the schema illustrated in Figure 2. The PV model is based in a first step on calculation of sun position. Taking this position, orientation angles of the PV panel, and horizontal irradiation into consideration, the global irradiation received by the surface can be calculated. In a second step, the temperature and efficiency of the module are calculated based on module type and ambient information (temperature and velocity of wind). As a result, the PV model can be simulated to calculate the 


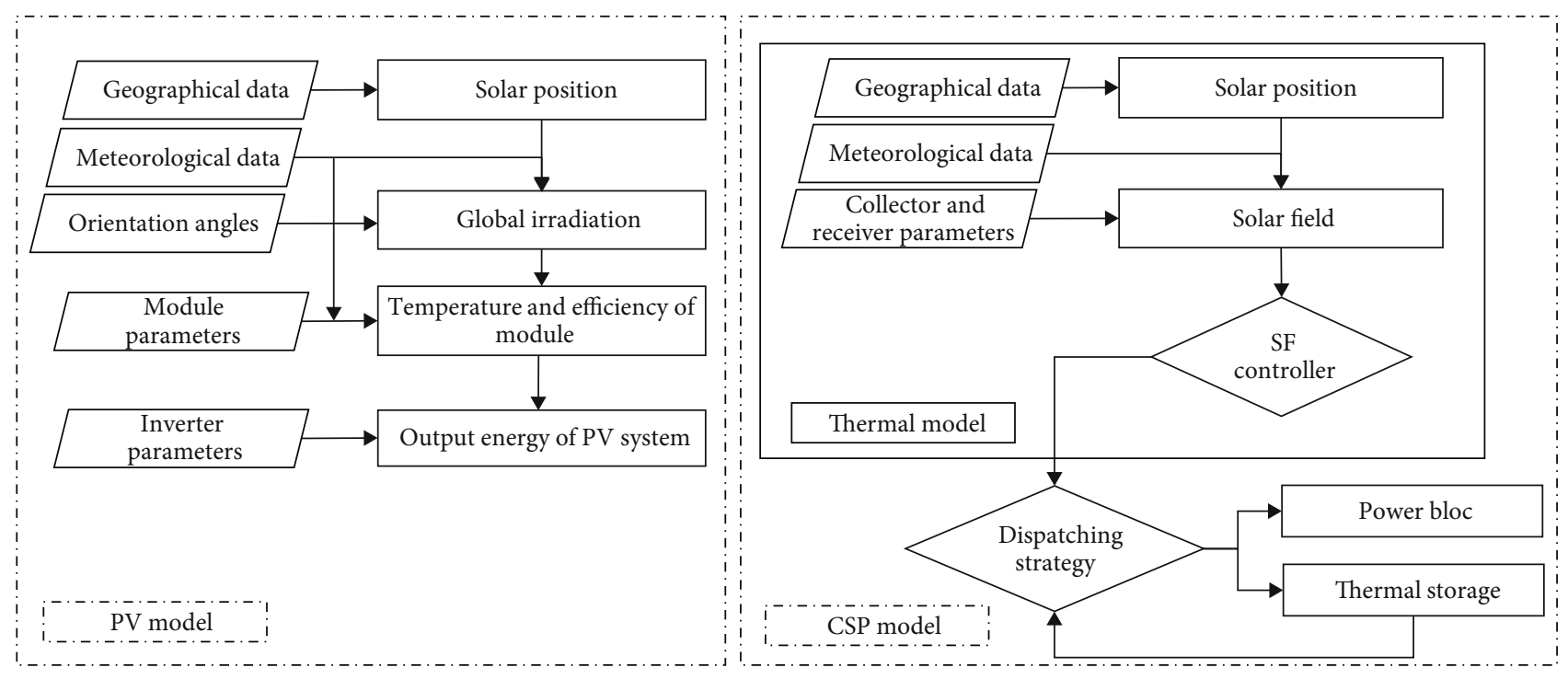

FIgURE 2: Model of PV and CSP plants.

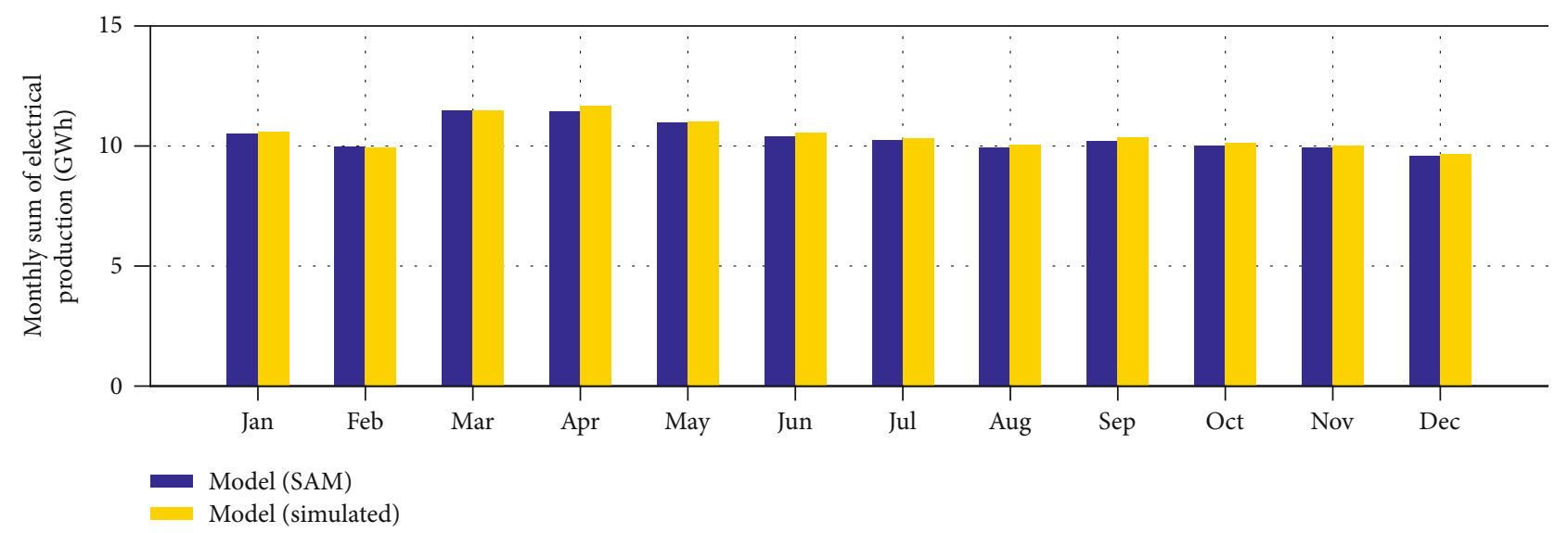

(a)

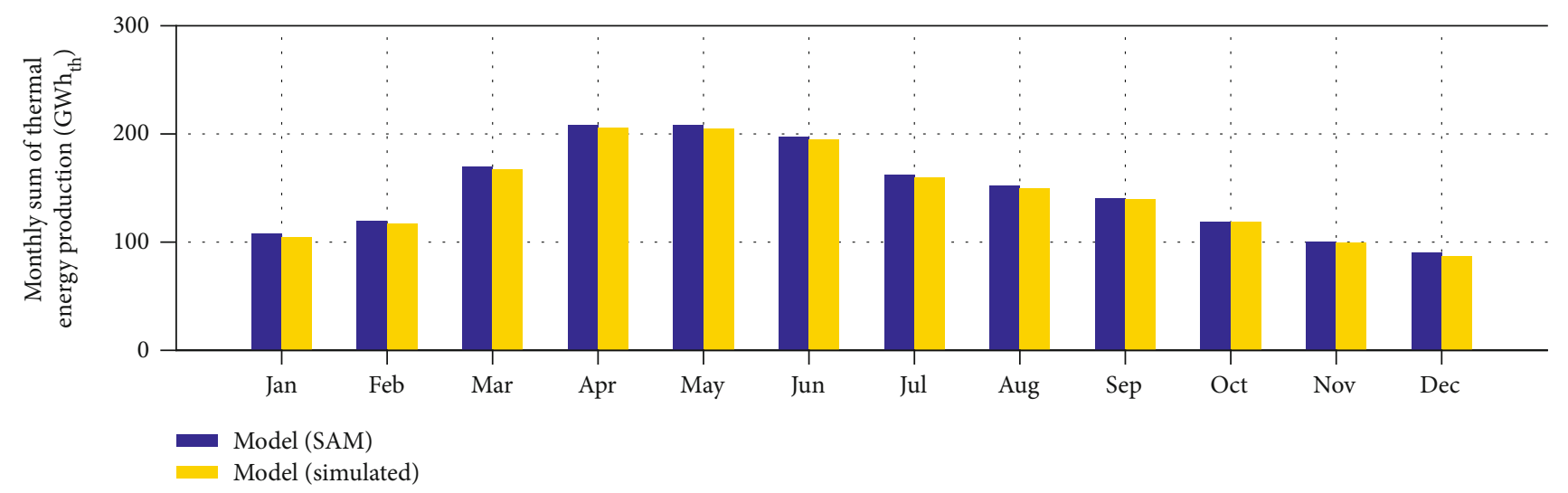

(b)

FIGURE 3: Monthly sum of energy production of the (a) $70 \mathrm{MW}$ PV and (b) $160 \mathrm{MW}$ CSP.

electrical output energy of the PV system. The CSP model implemented to calculate the sun position in the same way calculated by the PV model. The solar field is the main block that calculates the thermal power produced based on sun position angles, direct normal irradiance, collector orientation, and characteristic parameters of collector and receiver. 
Table 2: Main parameters of the PV model.

\begin{tabular}{lc}
\hline Parameter & Value \\
\hline Module [38] & \\
Nominal efficiency & $15.33 \%$ \\
Module area & $1.63 \mathrm{~m}^{2}$ \\
Module length & $1.66 \mathrm{~m}$ \\
Module width & 0.98 \\
Temperature coeff. of power & $-0.456 \%$ \\
Total irradiance ref & $1000 \mathrm{~W} / \mathrm{m}^{2}$ \\
Cell temperature ref & $25^{\circ} \mathrm{C}$ \\
& $a=-3.56$ \\
Module structure and mounting [31] & $b=-0.075$ \\
& $\Delta T=3$ \\
Tilt angle & $30^{\circ}$ \\
Azimuth angle & $0^{\circ}(\mathrm{south})$ \\
Inverter & \\
Inverter efficiency & $96.3 \%$ \\
Max AC power & $5000 \mathrm{~W}$ \\
Max DC power & $5173 \mathrm{~W}$ \\
Losses & \\
Factor losses [17] & 0.8 \\
\hline
\end{tabular}

The utility of solar field controller (SF controller) is to calculate the inlet and outlet temperature solar field and determine the condition operation for the solar field and as a result estimate the net energy collected by the heat transfer fluid. To use thermal power efficiently, a strategy of dispatching is obligatory. Based on the operational mode of the plant (start-up, day operation, and night operation), the dispatching strategy of a CSP plant alone prioritizes the power bloc over the TES charge; so, the net power collected is sent directly to the turbine and only the excess power above its maximum thermal power input is sent to charge the TES.

The performance of PV and CSP plants highly influences the final simulation process, in terms of annual energy and LCOE calculation. For this reason, the models proposed in the previous sections have been validated via the SAM tools [35] that have been used through many researches $[11,39]$. In particular, Figure 3 illustrates the monthly values of the energy production achieved with SAM and proposed models. Results of Figure 3 refer to the main system parameters reported in Tables 2 and 3. However, the default values for evaluating both the PV losses and the solar field thermal losses have been used for the SAM simulation.

The monthly production of both the CSP and the PV plants calculated for the Ouarzazate case has presented a good matching between SAM and proposed model results. In particular, the small difference is due to the simplification of the model and the ignorance of some errors such as the simplification of solar position calculation, the ignorance of inverter energy consumption at night and shadowing losses for the PV plant, and the use of empirical equations to calculate the receiver and pipe losses for the CSP model. Ouarzazate location is characterized by a desert climate; the
TABle 3: Main parameters of the PV model.

\begin{tabular}{|c|c|}
\hline Parameter & Value \\
\hline \multicolumn{2}{|l|}{ Solar field } \\
\hline Design irradiation & $950 \mathrm{~W} / \mathrm{m}^{2}$ \\
\hline Design ambient temperature & $25^{\circ} \mathrm{C}$ \\
\hline Design wind velocity & $5 \mathrm{~m} / \mathrm{s}$ \\
\hline Solar multiple & 2 \\
\hline Row spacing & $15 \mathrm{~m}$ \\
\hline \multicolumn{2}{|l|}{ Solar collector } \\
\hline Type & Euro trough ET 150 \\
\hline Reflective aperture area & $817.5 \mathrm{~m} 2$ \\
\hline Collector assembly aperture & 5.75 \\
\hline Collector assembly length & $150 \mathrm{~m}$ \\
\hline $\begin{array}{l}\text { Number of modules per } \\
\text { collector assembly }\end{array}$ & 8 \\
\hline Optical efficiency & $86 \%$ \\
\hline \multicolumn{2}{|l|}{ Thermal receiver } \\
\hline Type & Schott PTR70 \\
\hline Efficiency & $93 \%$ \\
\hline HTF type & DOWTHERM A \\
\hline $\begin{array}{l}\text { Minimum operating } \\
\text { temperature of HTF }\end{array}$ & $12^{\circ} \mathrm{C}$ \\
\hline $\begin{array}{l}\text { Maximum operating } \\
\text { temperature of HTF }\end{array}$ & $400^{\circ} \mathrm{C}$ \\
\hline \multicolumn{2}{|l|}{ Power block } \\
\hline Cycle type & Rankine cycle \\
\hline Cycle efficiency & $40 \%$ \\
\hline Design inlet temperature & $391^{\circ} \mathrm{C}$ \\
\hline Design outlet temperature & $293^{\circ} \mathrm{C}$ \\
\hline \multicolumn{2}{|l|}{ Storage } \\
\hline Thermal storage fluid & $\begin{array}{c}\text { Hitec solar salt } \\
\left(60 \% \mathrm{NaNO}_{3}, 40 \% \mathrm{KNO}_{3}\right)\end{array}$ \\
\hline Storage tanks & 2 \\
\hline Efficiency & 0.985 \\
\hline Storage capacity & $3 \mathrm{~h}$ \\
\hline
\end{tabular}

thermal energy produced by the solar field between March and July is maximum due to the high value of DNI in this period (Figure 1). The PV modules are able to exploit the global solar radiation, which makes the effect of PV production by the seasonal influence of the solar source less relevant. The gap between winter and summer energy production is low.

The simulation of hypothetical CSP plant $(160 \mathrm{MW})$ is estimated to produce $489 \mathrm{GWh}$; the result obtained from simulation is compared to similar plant available in Ouarzazate (NOOR 1) that has the same system parameters [40]; the annual energy variation percentage is $5.9 \%$; the difference in result is due to the uncertainty in the meteorological data assumed and mistaken assumptions about loss parameters.

3.2. Case Study. In this section, we identify the design parameters that affect the annual performance of PV, CSP, and PVCSP plants in terms of energy generation and economic cost. 


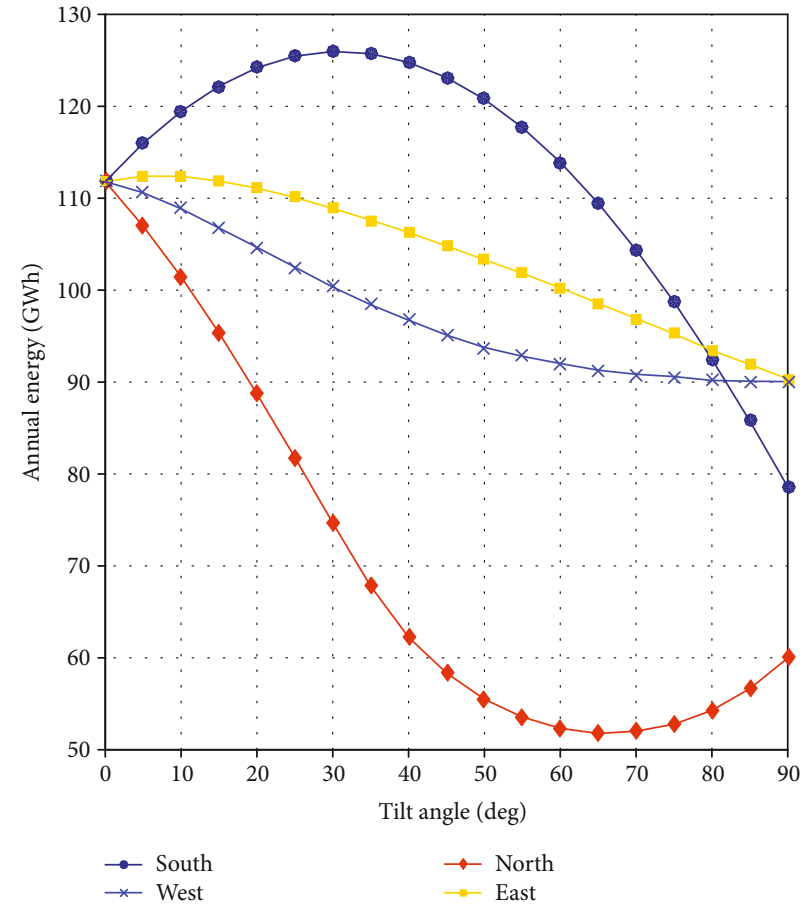

(a)

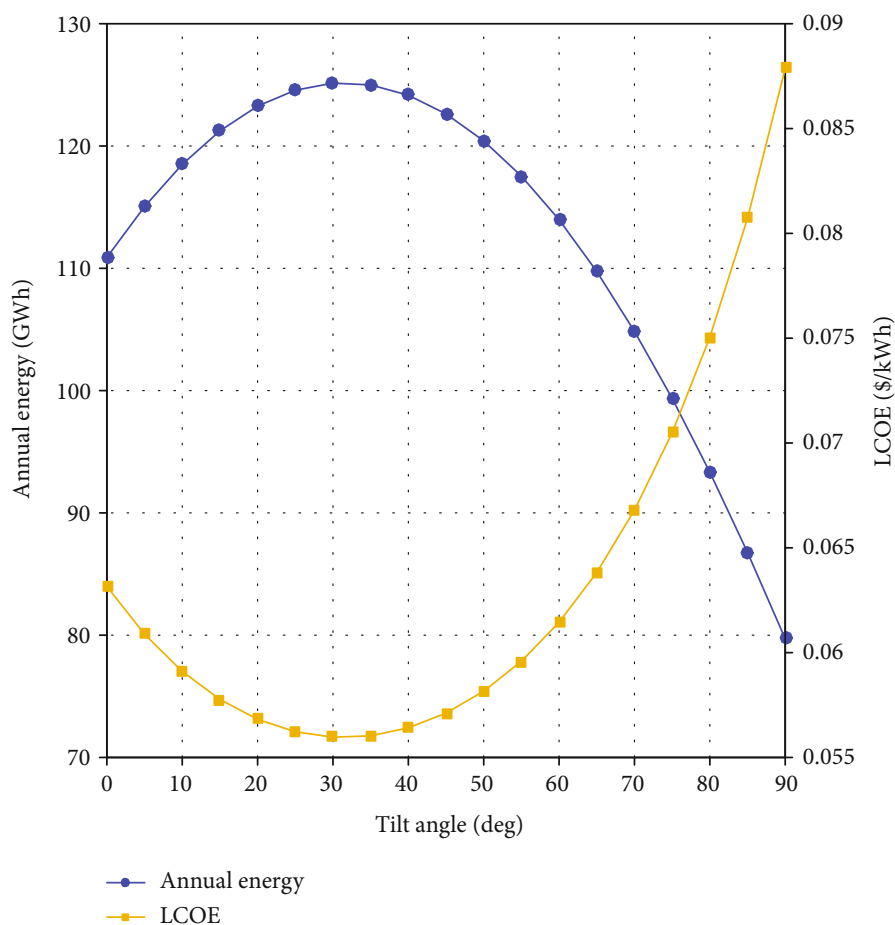

(b)

Figure 4: (a) The variation of annual energy for the PV system alone with tilt angle for different orientations. (b) The variation of annual energy and LCOE for the PV system alone with tilt angle for south orientation.

(i) Orientation angles involve the tilt and direction of the PV panel

(ii) Solar multiple is defined as the ratio of the actual aperture area of the mirrors to the reference mirror aperture area [41]

(iii) TES capacity is the capacity of the storage tank in terms of the frequent hours. This parameter involves the storage energy capacity

(iv) Fraction of hybridization is the ratio between PV or CSP installed capacity and PV-CSP nameplate capacity

The section's objective is to understand the influence of those parameters for a given capacity of a PV and a CSP plant alone and study their effect on PV/CSP hybridization. The results of various combinations of thermal storage hours, solar multiple, and fraction of hybridization have been discussed in details to determine the optimal configuration and study the profitability of the PV/CSP plant for Ouarzazate location.

3.2.1. Case 1: $P V$ Alone. The main system parameters reported in Table 2 are used to simulate a $70 \mathrm{MW}$ PV array by varying the orientation angles of the PV module. Figure 4(a) illustrates the variation of annual energy for a PV plant with a tilt angle for different orientations (south, north, east, and west). The annual produced energy by orientating PV modules to the south $\left(\gamma s=0^{\circ}\right)$ outperforms the other orientations due to less wasted energy. Figure 4(b) shows the variation of annual energy and LCOE for the PV plant with a tilt angle for south orientation.

The annual produced energy increases in the tilt angle interval $\left[0^{\circ}, 30^{\circ}\right]$ from $111 \mathrm{GWh}$ to $125 \mathrm{GWh}$ of annual energy; once the tilt angle is greater than $30^{\circ}$ the annual energy decreases significantly. The curve representation of the annual energy from the PV system and LCOE are opposites, when the annual energy decreases the LCOE increases and vice versa.

The lowest LCOE is $0.056 \$ / \mathrm{kWh}$ and the highest annual energy is $125 \mathrm{GWh}$; the cost effectiveness and production profitability are achieved with a tilted angle of $30^{\circ}$ and southern orientation. This orientation will be used for the rest of the study, mainly because it is the most optimal.

To minimize the cost of installing the tracker, the PV modules must be oriented to an optimal orientation which makes the system provide the maximum annual energy with the low LCOE. The orientation angles affect the annual energy output and LCOE typically depending on the system's location and configuration.

3.2.2. Case 2: CSP Alone. The main system parameters of the CSP plant reported in Table 3 are used to simulate a $150 \mathrm{MW}$ parabolic trough plant by varying the solar multiple and TES capacity. The dispatching strategy implemented prioritizes the power bloc over the TES charge.

Figure 5 shows the influence of TES capacity on the power system generated during a typical day for two cases $(\mathrm{TES}=6 \mathrm{~h}$ and TES $=12 \mathrm{~h}$ ) with SM equal to 3. In Figure 5(a) $(\mathrm{TES}=6 \mathrm{~h})$, it is clear that from $11 \mathrm{pm}$ the system does 


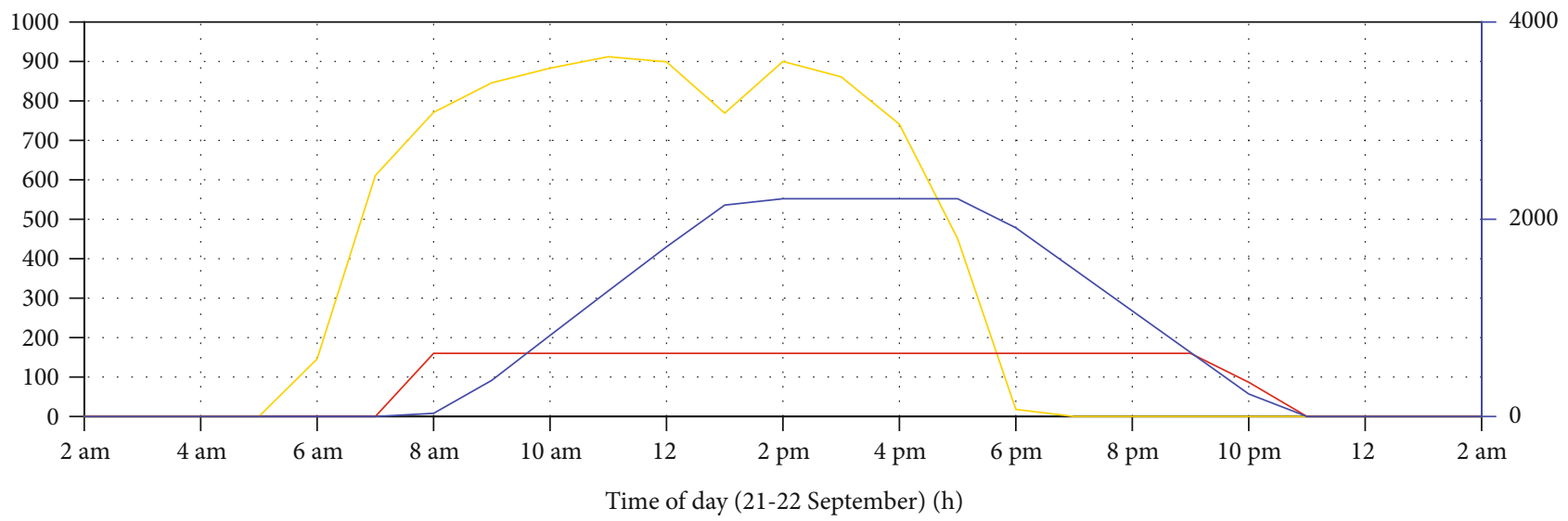

DNI $\left(\mathrm{W} / \mathrm{m}^{2}\right)$

- Generated energy $\left(\mathrm{MWh}_{\mathrm{el}}\right)$

- Stored energy $\left(\mathrm{MWh}_{\mathrm{th}}\right)$

(a)

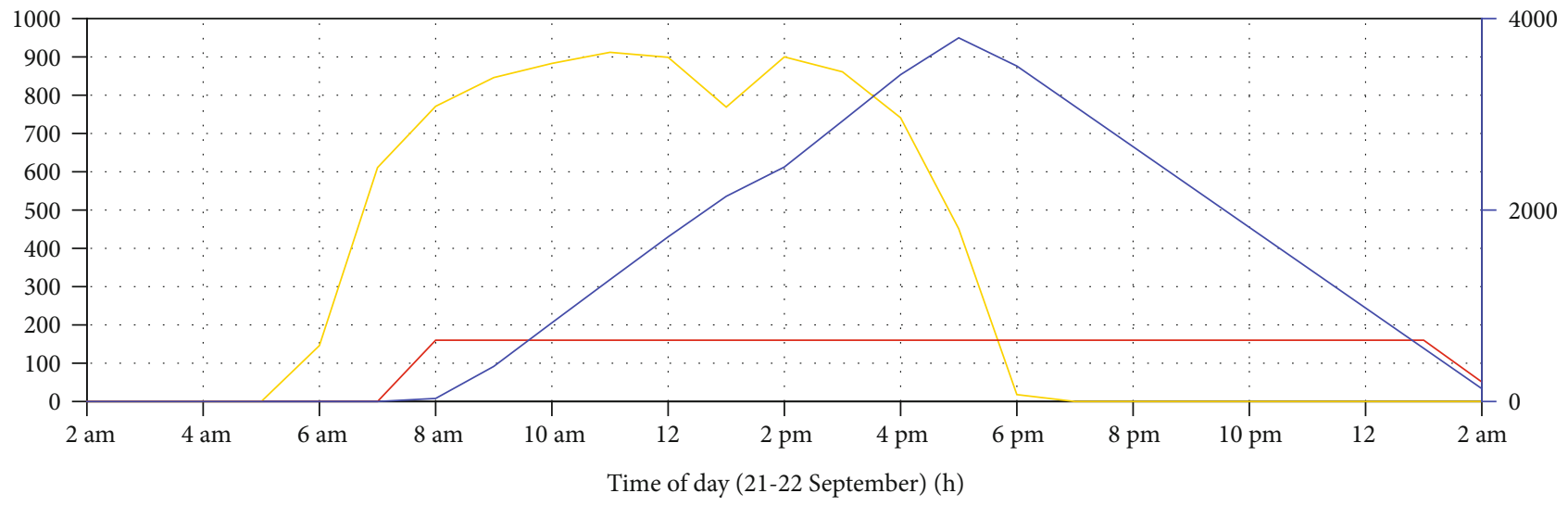

- DNI $\left(\mathrm{W} / \mathrm{m}^{2}\right)$

- Generated energy $\left(\mathrm{MWh}_{\mathrm{el}}\right)$

- Stored energy $\left(\mathrm{MWh}_{\mathrm{th}}\right)$

(b)

FIGURE 5: The influence of storage capacity on the system energy generated: (a) TES $=6 \mathrm{~h}$, (b) TES $=12 \mathrm{~h}(\mathrm{CSP}$ plant with $150 \mathrm{MW}$ and SM $=3$ ).

not generate more power even though the plant has a storage capacity of $8 \mathrm{~h}$, because during the period of $1 \mathrm{pm}$ to $5 \mathrm{pm}$, the stored energy has reached the maximum storage capacity which is in the order of $2200 \mathrm{MWh}_{\mathrm{th}}(6 \mathrm{~h})$; therefore, the excess of field energy produced is dumped. In Figure 5(b), from $11 \mathrm{pm}$, the system continues to generate electricity; the system generates $95 \%$ of design power from $11 \mathrm{pm}$ to $1 \mathrm{am}$; this could be explained by the fact that this surplus is generated by the stored energy; the total energy generated by field is fully utilized by power block and storage.

A plant with $\mathrm{SM}=3$ and TES of $12 \mathrm{~h}$ allowed to have a daily higher energy; this energy will be distributed between the power supply of the turbine and the recharge of the storage tank. If the value of TES is lower than the optimum value, the excess of energy will be dumped because the storage is not large enough. In this case, the storage capacity must be large to utilize the excess solar power and to prohibit some mirrors from defocus.
The choice of solar multiple and TES capacity is linked, and it strongly affects the annual energy produced and the LCOE.

Applying the CSP model, the annual energy and LCOE are calculated for various values of SM and thermal storage capacity; the result of different simulations is illustrated in Figures 6 and 7. According to them, when SM equal to 1, the annual energy remains constant for different thermal storage size values, but the cost increases substantially because of the higher initial investment in thermal storage. In this case, there is no need to invest in thermal storage.

When $S M>1$ and in the absence of thermal storage $(\mathrm{TES}=0 \mathrm{~h})$, the annual energy value is minimal but the LCOE is maximal for all configuration, because some mirrors have to be defocused, and consequently, the excess of solar thermal energy have not been utilized. In this case, there is no need to oversize the plant. The optimal configuration for a CSP plant without a storage system is to have a SM equal to 1 . 


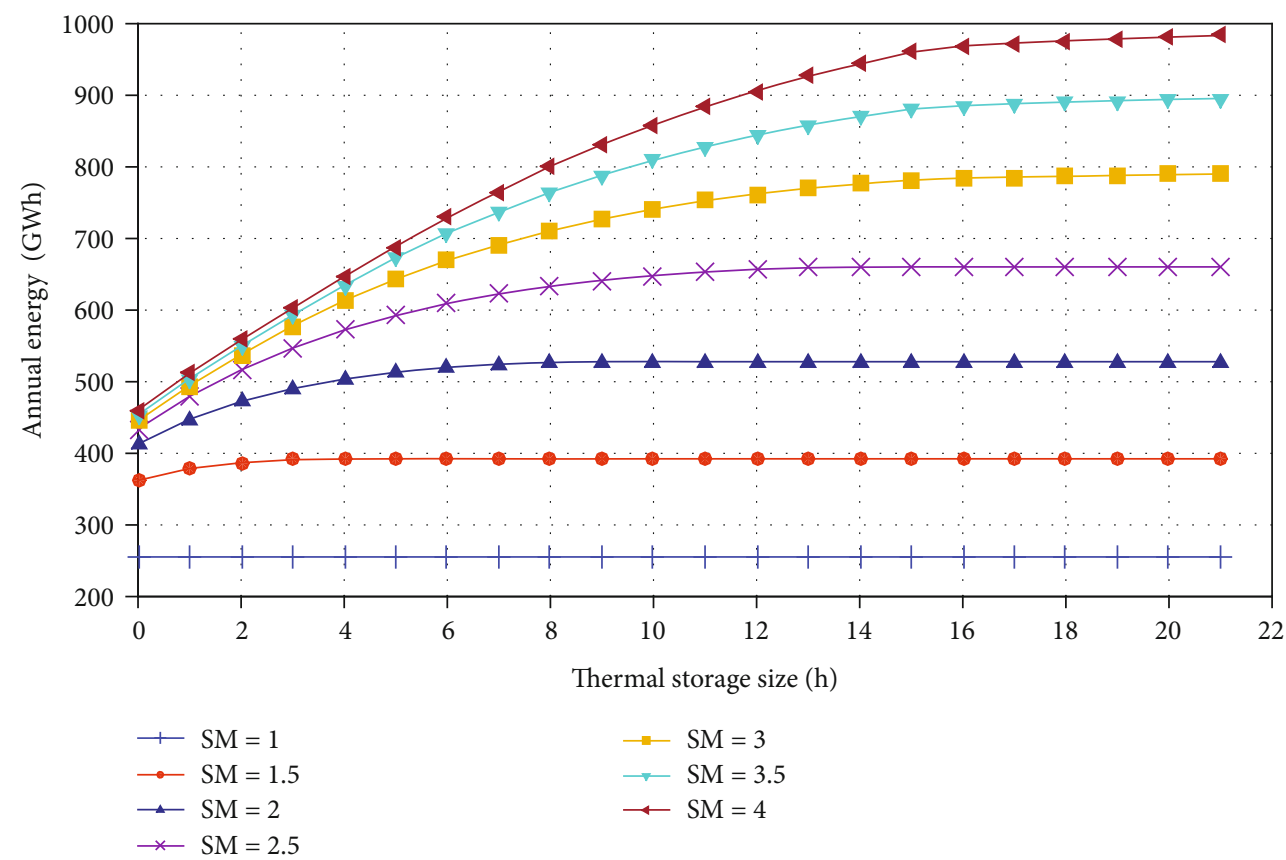

FIGURE 6: Variation of annual energy with thermal storage size for various SMs.

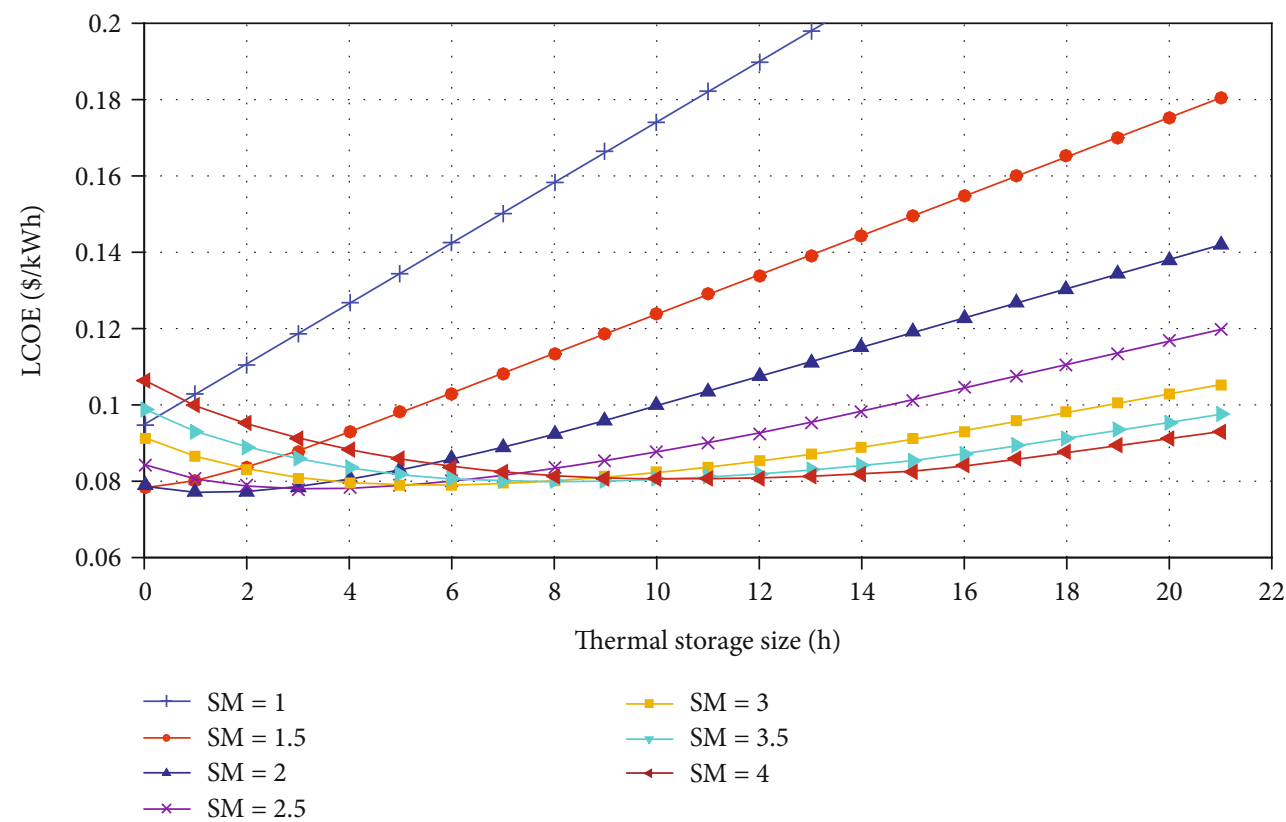

FIGURE 7: Variation of LCOE with thermal storage size for various SMs.

TABLE 4: Summarization of optimal results of each simulation.

\begin{tabular}{lccccccc}
\hline Capacity installed: $150 \mathrm{MW}$ & \multicolumn{1}{l}{} \\
\hline SM & 1 & 1.5 & 2 & 2.5 & 3 & 3.5 & 4 \\
TES & 0 & {$[1,4]$} & {$[2,6]$} & {$[5,9]$} & {$[7,12]$} & {$[13,16]$} & {$[15,17]$} \\
Annual energy $(\mathrm{GWh})$ & 255 & {$[378.8,392.3]$} & {$[490,520]$} & {$[592,640]$} & {$[691,762]$} & {$[858,885]$} & {$[960,973]$} \\
LCOE $(\$ / \mathrm{kWh})$ & 0.09 & {$[0.08,0.092]$} & {$[0.077,0.082]$} & {$[0.078,0.083]$} & {$[0.079,0.083]$} & {$[0.081,0.085]$} & {$[0.081,0.083]$} \\
\hline
\end{tabular}




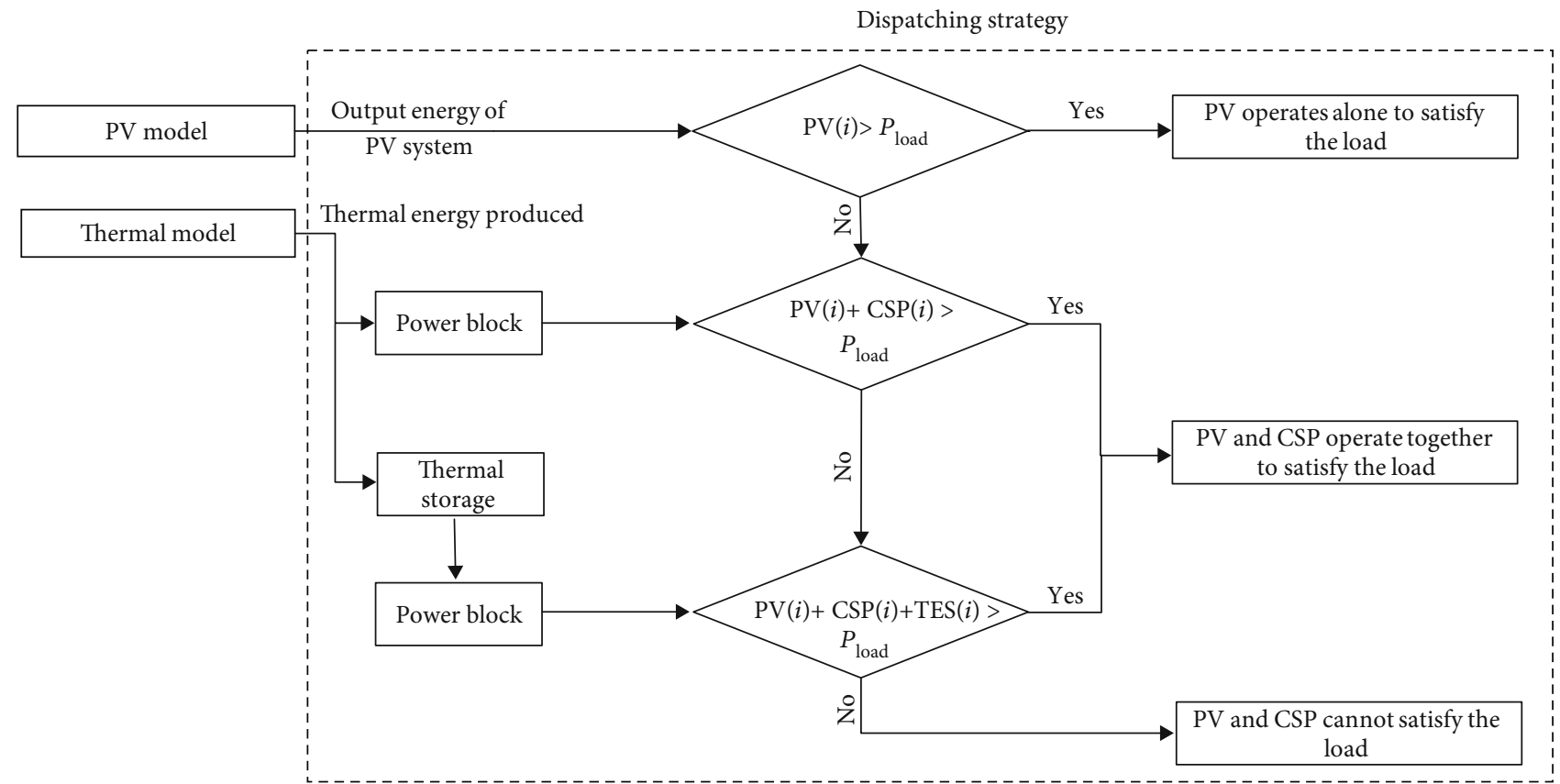

Figure 8: Model of the PV-CSP plant.

TABle 5: Simulated plant configurations.

\begin{tabular}{|c|c|c|c|c|}
\hline Fraction of hybridization & PV capacity (MW) & Turbine net capacity (MW) & Solar multiple & TES (h) \\
\hline Scenario 1 & 300 & 0 & \multirow{5}{*}[1.5,2,2.5,3,3.5,4]{} & - \\
\hline Scenario 2 & 225 & 75 & & \multirow{4}{*}[8,10,12,14]{} \\
\hline Scenario 3 & 150 & 150 & & \\
\hline Scenario 4 & 75 & 225 & & \\
\hline Scenario 5 & 0 & 300 & & \\
\hline
\end{tabular}
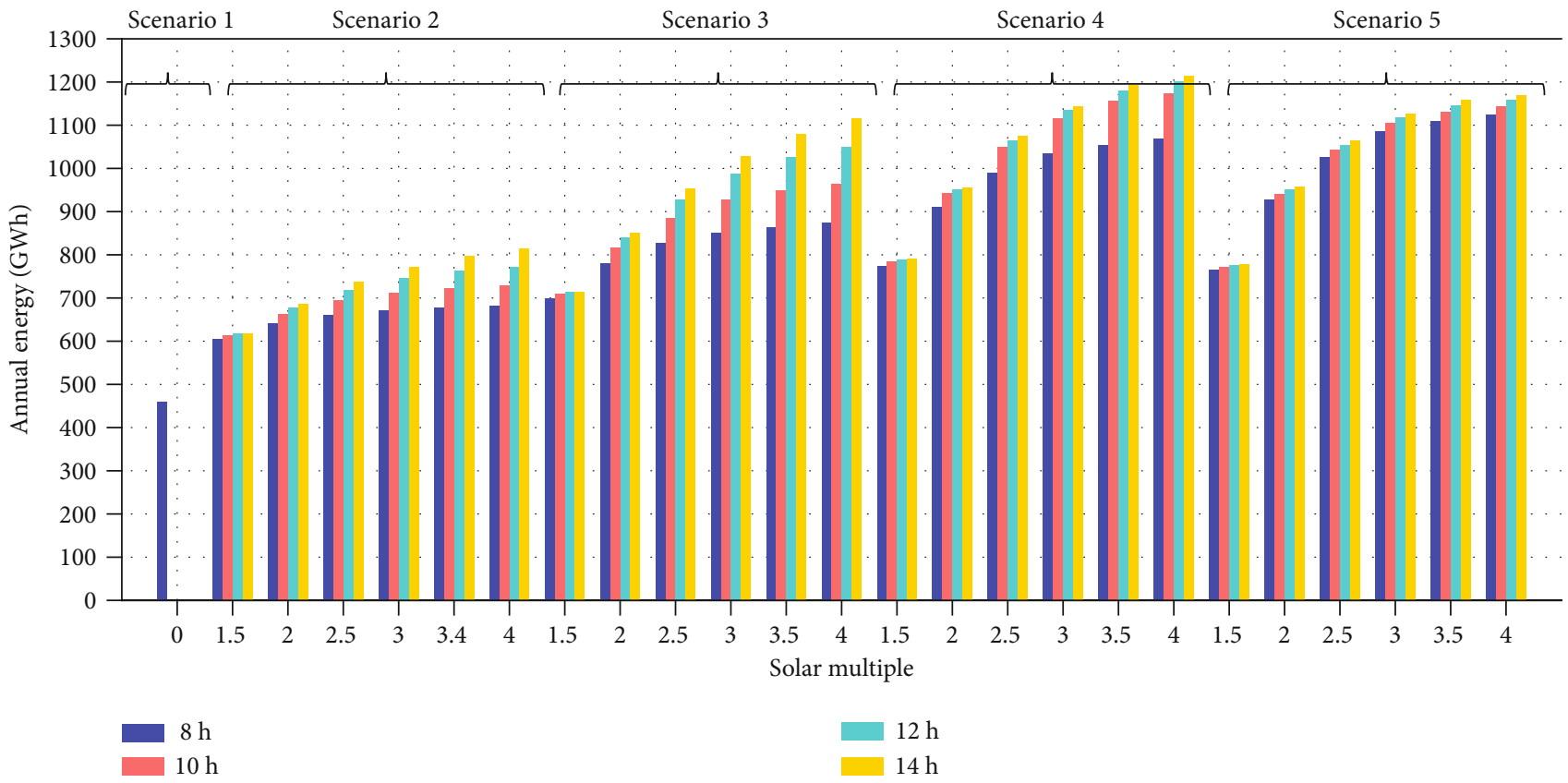

FIgURE 9: The annual energy from all simulated configurations. 


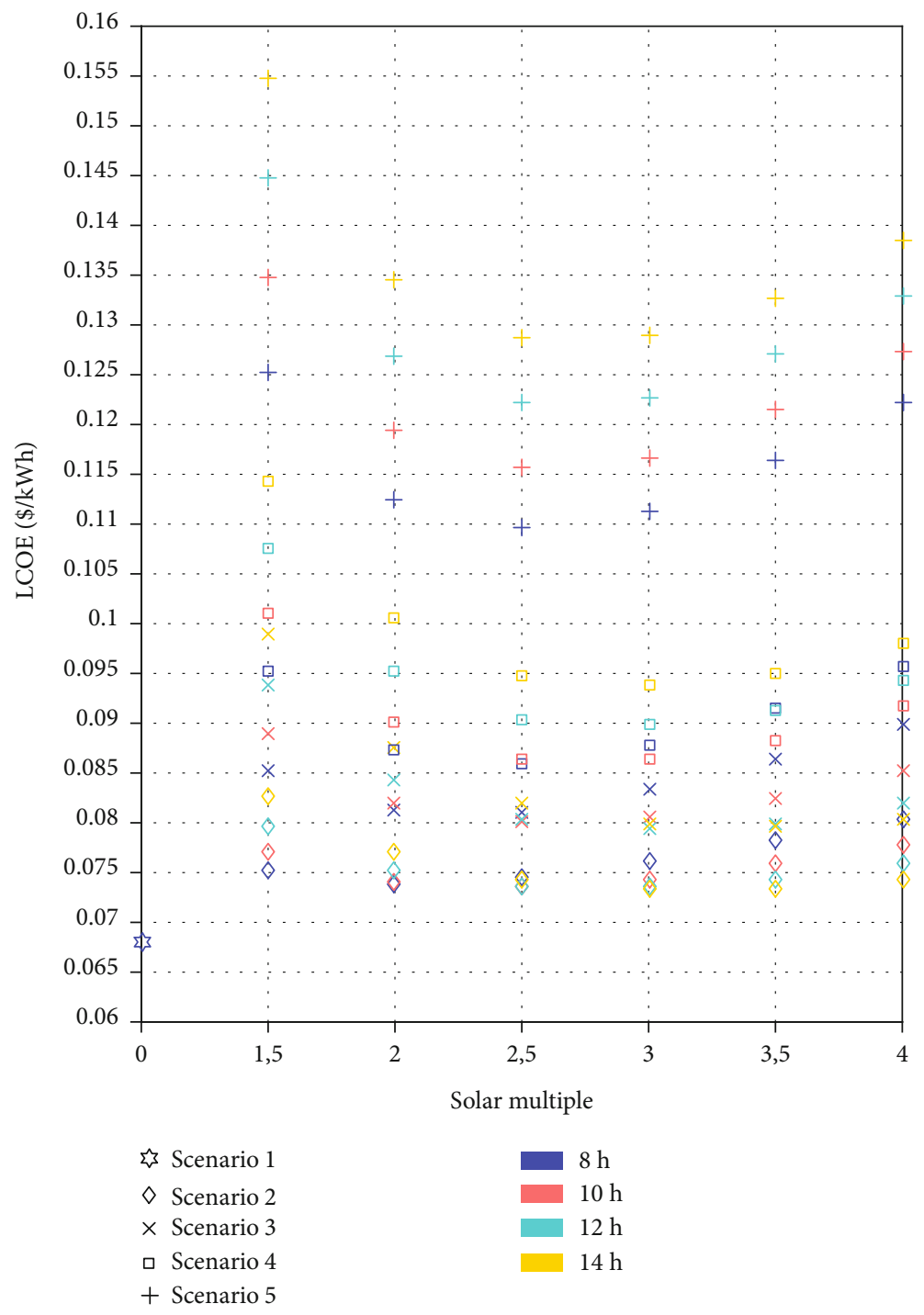

FIGURE 10: The LCOE from all simulated scenarios.

As it can be seen from Figures 6 and 7, for all solar multiples studied (except $\mathrm{SM}=1$ ), the annual energy values increase with the increasing thermal storage size until a certain value of thermal storage size was reached; the annual energy remains constant; the values of LCOE decrease with increasing thermal storage size until a certain value; they start rising again with a further increase in thermal storage size. We can conclude that, for each multiple solar value, we will have an optimal interval of the storage capacity for which the plant produces maximum energy at a minimum cost relative to the capacity installed. The trade-off between the solar multiple and the storage capacity must be balanced against the annual energy generated. Table 4 summarizes the optimal combinations of each simulation.

3.2.3. Case 3: PV-CSP Hybrid. To study the concept of hybridization PV-CSP, the simulation consists to couple the PV plant with the CSP plant and dispatch the energy generated by the two systems. The operation strategy was proposed and implemented to take advantage of the energy produced by both plants in an optimal way. In the morning, when the PV system starts to produce electricity, if the PV production is large enough to cover the load, the CSP power block is shut down, but if the PV production is not sufficient to cover the load, the CSP system covers the other missing load. On the other hand, the exceeded thermal energy from the receiver is stored in the thermal energy storage tank. In the evening, when the PV system cannot deliver the electricity demanded, the CSP uses the energy stored during the day to cover the load throughout the night until the sun rises again. The model of the PV-CSP plant is established according to the schema illustrated in Figure 8.

The key of this hybridization is the thermal energy storage from the CSP plant; it permits to dispatch the electricity generation from day to night, making the CSP plant appropriate for a combination with a PV plant without any storage system, which can only operate during daytime.

To demonstrate the cost effectiveness and production profitability of the PV-CSP plant, different simulations are implemented in the examination of hybridization PV-CSP 


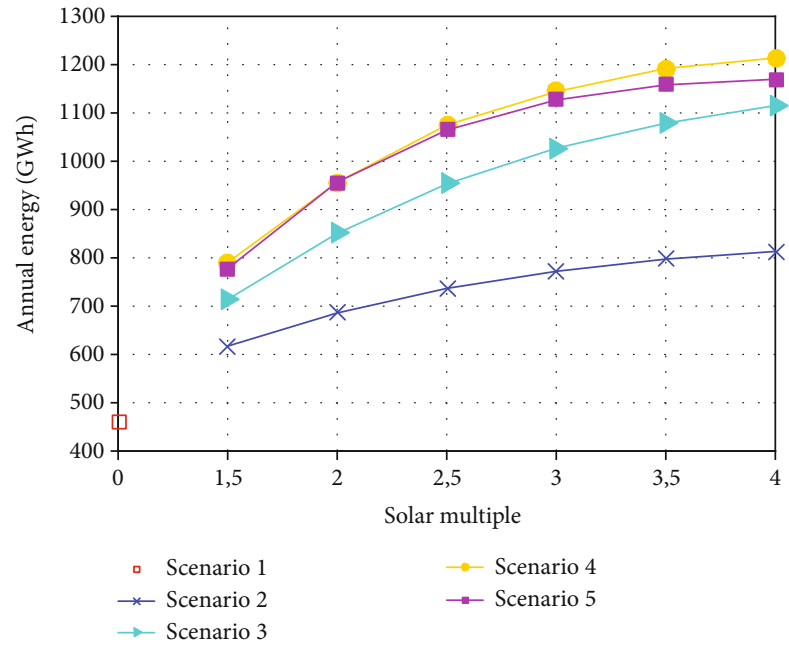

(a)

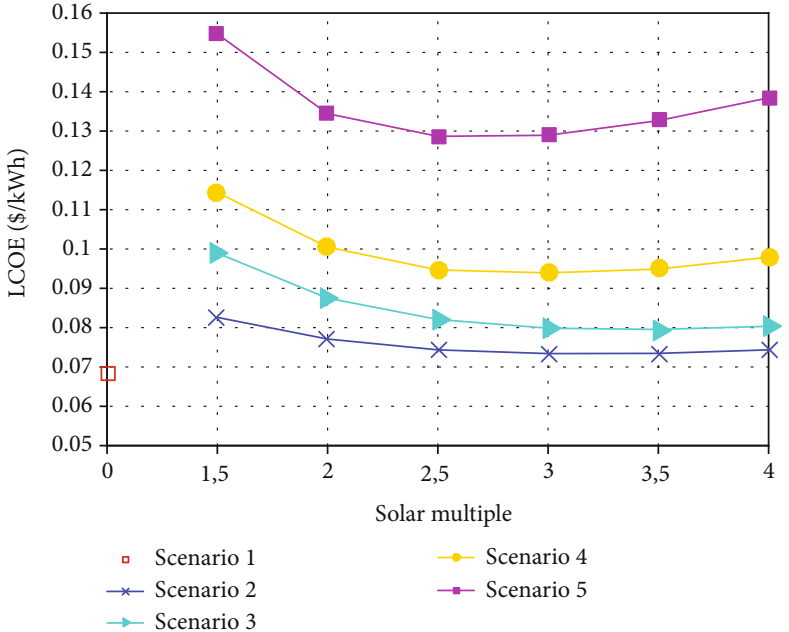

(b)

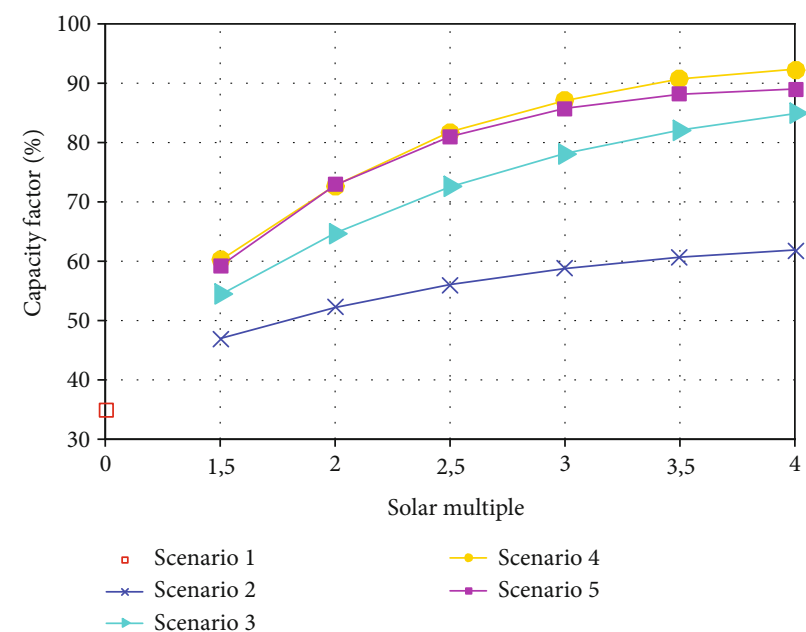

(c)

Figure 11: The variation of (a) annual energy, (b) LCOE, and (c) capacity factor according to solar multiple for TES $=14 \mathrm{~h}$.

and compare the electricity production from the PV plant alone, the CSP plant alone, and the hybrid PV-CSP plant. Additionally, an economic analysis of all plants is realized to demonstrate the cost effectiveness of the hybridization $\mathrm{PV} / \mathrm{CSP}$.

The simulation is based on the satisfaction of a baseload of $150 \mathrm{MW}$ by three types of plant, a PV plant, a CSP plant, and a hybrid PV-CSP, and the surplus generated energy above $150 \mathrm{MW}$; it will be stored or dumped if there is no storage system or the storage is fully utilized. Indeed, three scenarios have been simulated in the case of a hybrid plant with different PV and CSP installed capacity, to study the impact of the fraction of hybridization on the PV-CSP plant performances. Table 5 provides the parameters of simulated configurations with various values of solar multiple and TES capacity for different scenarios.

The results obtained from the different simulations are presented in Figures 9 and 10 to discuss the power plant technoeconomic performances. Figures 9 and 10 illustrated the annual energy and LCOE, respectively, from all simulated configurations.
According to Figure 9, for all configurations (except scenario 1), the annual energy output increases greatly with increasing solar multiple, whereas increasing the thermal storage size has only a minor effect for PV-CSP and CSP alone. To further visualize this variation and study the baseload performances, we used Figure 11 that represents the variation of annual energy, LCOE, and capacity factor according to solar multiple specifically for TES $=14 \mathrm{~h}$ . Although there are technically $300 \mathrm{MW}$ installed (CSP and PV power), the capacity factor of plants is calculated as follows on the assumption that the plant has $150 \mathrm{MW}$ of installed capacity, however, due to the purpose of this study to have a "virtual" power plant that satisfies a baseload capacity of $150 \mathrm{MW}$.

From Figure 10, the minimum cost $0.0681 \$ / \mathrm{kWh}$ is obtained by scenario 1 , due to the low cost of photovoltaic technology; the minimum cost $0.073 \$ / \mathrm{kWh}, 0.079 \$ / \mathrm{kWh}$, $0.086 \$ / \mathrm{kWh}$, and $0.109 \$ / \mathrm{kWh}$, for scenarios 2, 3, 4, and 5, respectively, are obtained by the smaller storage size (TES $=8 \mathrm{~h}$ ) due to the high investment costs of the larger TES systems. 
From Figure 11, in scenario 1, we obtain a minimum energy because the system does not have a system of electrical energy storage; consequently, the excess energy during the day cannot be stored, and the system cannot satisfy the load during the night, which is reflected by a minimum capacity factor.

In scenario 5, we obtain higher energy when having solar multiple $(3,3.5,4)$ for all TES values, but according to Figure 10, it is the highest cost; the optimal solar multiple for scenario 5 is between 2 and 3 with only small differences due to the size of the TES.

In scenario 2, the PV capacity installed is 3 times the turbine net capacity, and in scenario 3, the PV capacity installed is the same to the turbine net capacity; by comparing scenario 2 and scenario 5 , we can conclude that scenario 5 produces globally more energy than scenario 2 for each solar multiple (1.5 excluded). With that being said, scenario 2 requires the lowest cost of all four scenarios (2, 3, 4, and 5); it is the same when comparing scenario 3 and scenario 5 for all solar multiples; scenario 3 has a lower cost than scenario 5 for each solar multiple by looking at Figures 10 and 11. In scenario 4 , the turbine net capacity is 0.75 smaller than the turbine net capacity in scenario 5, when comparing them for each solar multiples $(1.5,2,2.5)$; scenario 4 has a lower cost than scenario 5 for the same amount of annual produced energy, but, from a solar multiple equal to 3 , scenario 4 produces a higher annual energy due to the high energy dumped by scenario 5 .

For $\mathrm{SM}=4$, the capacity factor is increased by $3.6 \%$ according to scenario 4 compared with scenario $5(\mathrm{SM}=4)$ and the LCOE is decreased by $41.3 \%$ which results that the scenario 4 has a high cost-effective performance. The $\mathrm{CSP} / \mathrm{PV}$ hybrid power plants offer a higher capacity factor of about $92.4 \%$ that is achieved by scenario $4(\mathrm{SM}=4$, TES $=14 \mathrm{~h}$ ), which has shown that a continuous power supply of load over several days is possible. The CSP/PV installation is therefore a suitable baseload plant.

Overall, hybridization is the smarter choice based on the fact that it requires a moderate cost and produces a higher amount of energy; as for the optimal implant, scenario 4 is the most adequate in terms of annual energy and capacity factor. The choice of optimal configuration may change according to the objectives: for more energy and slightly higher cost, we would opt for scenario 4; for a much lower cost and slight lower amount of energy, we would encourage the choice of scenario 2.

\section{Conclusion}

The analysis for a solar plant located in Ouarzazate using a model simulated is well presented. Orientations angle, solar multiple, thermal storage size, and fraction of hybridization are considered the principal design parameters; the objective is to study their effect on the PV, CSP, and PVCSP plants in terms of cost and energy production. The findings are as follows:

(i) The orientation angle of PV panels highly influences the annual energy and the LCOE. The south orientation and a tilt angle around $30^{\circ}$ are the optimal orien- tation to maximize the annual energy and minimize the LCOE for Ouarzazate city

(ii) The strength of CSP over other renewable energy technologies is the TES system that has an utmost impact on CSP plant performance; the profitability of CSP increases by increasing the TES size

(iii) The choice of TES and solar multiple is relatively linked; per each value of solar multiple, a TES interval is the most adequate in terms of the annual energy cost ratio

(iv) The combination of a PV and a CSP plant provides a dispatching energy with a lower LCOE than the CSP alone

(v) The hybridization fraction highly influences the performance of the PV-CSP hybrid plant. The increase of PV share results a huge reduction in the LCOE, contrary to an increase of CSP share which leads to an enormous increase in annual energy for the same capacity installed

The location of Ouarzazate has an excellent potential in terms of solar resources. The implementation of optimal configuration of the PV-CSP hybrid plant is a viable solution than the CSP alone. It will not only have an immense benefit to Morocco's economy but it will also be a huge new step to an ecofriendly community.

\section{Nomenclature}

PV: Photovoltaic

CSP: Concentrating solar power

SM: Solar multiple

TES: Thermal energy storage

RES: Renewable energy sources

RE: Renewable energy

LCOE: Levelized cost of energy

DNI: Direct normal irradiance

GHI: Global horizontal irradiance

DHI: diffuse horizontal irradiance

DC: Direct current

AC: Alternating current.

\section{Data Availability}

The meteorological data used to support the findings of this study are included within the article.

\section{Conflicts of Interest}

The authors declare that they have no conflicts of interest.

\section{References}

[1] R. Zhai, Y. Chen, H. Liu, H. Wu, and Y. Yang, “Optimal design method of a hybrid CSP-PV plant based on genetic algorithm considering the operation strategy," International Journal of Photoenergy, vol. 2018, Article ID 8380276, 15 pages, 2018. 
[2] L. Bird, M. Milligan, and D. Lew, "Integrating variable renewable energy: challenges and solutions," National Renewable Energy Lab. (NREL), Golden, CO, USA, 2013.

[3] E. Yuzugullu, Synergies for Sustainable Energy, Artech House, 2013.

[4] E. Kabir, P. Kumar, S. Kumar, A. A. Adelodun, and K.-H. Kim, "Solar energy: potential and future prospects," Renewable and Sustainable Energy Reviews, vol. 82, pp. 894-900, 2018.

[5] REN21, "Renewables 2018 global status report," http://www .ren21.net/gsr-2018.

[6] A. Ilas, P. Ralon, A. Rodriguez, and M. Taylor, Renewable Power Generation Costs in 2017, International Renewable Energy Agency (IRENA), Abu Dhabi, UAE, 2018.

[7] S. Goel and R. Sharma, "Performance evaluation of stand alone, grid connected and hybrid renewable energy systems for rural application: a comparative review," Renewable and Sustainable Energy Reviews, vol. 78, pp. 1378-1389, 2017.

[8] X. Ju, C. Xu, Y. Hu, X. Han, G. Wei, and X. du, “A review on the development of photovoltaic/concentrated solar power (PV-CSP) hybrid systems," Solar Energy Materials and Solar Cells, vol. 161, pp. 305-327, 2017.

[9] M. Mehos, C. Turchi, J. Jorgenson, P. Denholm, C. Ho, and K. Armijo, On the Path to SunShot: Advancing Concentrating Solar Power Technology, Performance, and Dispatchability, National Renewable Energy Laboratory, Golden, CO, USA, 2016, NREL/TP-5500-65688.

[10] M. Liu, N. H. Steven Tay, S. Bell et al., "Review on concentrating solar power plants and new developments in high temperature thermal energy storage technologies," Renewable and Sustainable Energy Reviews, vol. 53, pp. 1411-1432, 2016.

[11] C. A. Pan and F. Dinter, "Combination of PV and central receiver CSP plants for base load power generation in South Africa," Solar Energy, vol. 146, pp. 379-388, 2017.

[12] M. Orosz, "Photovoltaics and concentrating solar power: why hybridization makes sense," SPIE Newsroom, pp. 1-4, 2015.

[13] A. R. Starke, J. M. Cardemil, R. Escobar, and S. Colle, "Multiobjective optimization of hybrid CSP+PV system using genetic algorithm," Energy, vol. 147, pp. 490-503, 2018.

[14] W. Platzer, "PV-enhanced solar thermal power," Energy Procedia, vol. 57, pp. 477-486, 2014.

[15] W. J. Platzer, "Combined solar thermal and photovoltaic power plants - an approach to $24 \mathrm{~h}$ solar electricity?," in AIP Conference Proceedings, p. 070026, Cape Town, South Africa, 2016.

[16] F. Dominio, "Techno-economic analysis of hybrid PV-CSP power plants. Advantages and disadvantages of intermediate and peak load operation, [M.S. thesis]," Universitat Politècnica de Catalunya, 2014.

[17] M. Petrollese and D. Cocco, "Optimal design of a hybrid CSPPV plant for achieving the full dispatchability of solar energy power plants," Solar Energy, vol. 137, pp. 477-489, 2016.

[18] C. Parrado, A. Girard, F. Simon, and E. Fuentealba, " 2050 LCOE (levelized cost of energy) projection for a hybrid PV (photovoltaic)-CSP (concentrated solar power) plant in the Atacama Desert, Chile," Energy, vol. 94, pp. 422430, 2016.

[19] R. Zhai, H. Liu, Y. Chen, H. Wu, and Y. Yang, "The daily and annual technical-economic analysis of the thermal storage PVCSP system in two dispatch strategies," Energy Conversion and Management, vol. 154, pp. 56-67, 2017.
[20] A. Green, C. Diep, R. Dunn, and J. Dent, "High capacity factor CSP-PV hybrid systems," Energy Procedia, vol. 69, pp. 20492059, 2015.

[21] M. Hlusiak, M. Götz, H. A. B. Díaz, and C. Breyer, "Hybrid photovoltaic (PV)-concentrated solar thermal power (CSP) power plants: modelling, simulation and economics," in Proceedings of the 29th European Photovoltaic Solar Energy Conference and Exhibition, Amsterdam, Netherlands, 2014.

[22] A. R. Starke, J. M. Cardemil, R. Escobar, L. L. Lemos, and S. Colle, "Assessing the performance of concentrated solar power plants in selected locations of Chile," in THE 28th International Conference on Efficiency, Cost, Optimization, Simulation and Environmental Impact of Energy Systems, Pau, France, 2015.

[23] I. L. García, J. L. Álvarez, and D. Blanco, "Performance model for parabolic trough solar thermal power plants with thermal storage: comparison to operating plant data," Solar Energy, vol. 85, no. 10, pp. 2443-2460, 2011.

[24] T. Kousksou, A. Allouhi, M. Belattar et al., "Renewable energy potential and national policy directions for sustainable development in Morocco," Renewable and Sustainable Energy Reviews, vol. 47, pp. 46-57, 2015.

[25] Y. El Mghouchi, T. Ajzoul, and A. El Bouardi, "Prediction of daily solar radiation intensity by day of the year in twentyfour cities of Morocco," Renewable and Sustainable Energy Reviews, vol. 53, pp. 823-831, 2016.

[26] T. Bouhal, Y. Agrouaz, T. Kousksou et al., “Technical feasibility of a sustainable concentrated solar power in Morocco through an energy analysis," Renewable and Sustainable Energy Reviews, vol. 81, pp. 1087-1095, 2018.

[27] A. Lahnaoui, P. Stenzel, and J. Linssen, "Tilt angle and orientation impact on the techno-economic performance of photovoltaic battery systems," Energy Procedia, vol. 105, pp. 4312 4320, 2017.

[28] P. Gilman, SAM Photovoltaic Model Technical Reference, National Renewable Energy Lab. (NREL), Golden, CO, USA, 2015.

[29] J. A. Duffie, W. A. Beckman, and W. M. Worek, Solar Engineering of Thermal Processes, Fourth Edition, Wiley Online Library, 2013.

[30] J. J. Roberts, A. M. Cassula, J. C. F. Junior, and P. O. Prado, "Simulation and validation of photovoltaic system performance models," in Book of Abstracts and Proceedings of 11th Latin-American Congress on Electricity Generation and Transmission, p. 82, São José dos Campos, Brazil, 2015.

[31] J. A. Kratochvil, W. E. Boyson, and D. L. King, "Photovoltaic array performance model," Department of Energy, United States, 2004.

[32] A. B. Awan, M. Zubair, R. P. Praveen, and A. R. Bhatti, "Design and comparative analysis of photovoltaic and parabolic trough based CSP plants," Solar Energy, vol. 183, pp. 551-565, 2019.

[33] E. Bellos and C. Tzivanidis, "Alternative designs of parabolic trough solar collectors," Progress in Energy and Combustion Science, vol. 71, pp. 81-117, 2019.

[34] J. Wang, J. Wang, X. Bi, and X. Wang, "Performance simulation comparison for parabolic trough solar collectors in China," International Journal of Photoenergy, vol. 2016, Article ID 9260943, 16 pages, 2016.

[35] M. J. Wagner and P. Gilman, Technical Manual for the SAM Physical Trough Model, National Renewable Energy Lab. (NREL), Golden, CO, USA, 2011. 
[36] C. Kost, S. Shammugam, V. Jülch, H. Nguyen, and T. Schlegl, "Levelized cost of electricity renewable energy technologies," Fraunhofer Institute for Solar Energy Systems ISE, vol. 144, 2013.

[37] R. A. C. Caminos, Techno-economic assessment of hybrid photovoltaic/solar thermal power plants: modeling and potential for synergies, [M.S. thesis], 2017.

[38] Y. SOLAR, "Datasheet YGE 60 Cell 40mm SERIES," 2016, https://k2solar.com.au/wp-content/uploads/Yingli-SolarPOLY-YL250P-29b-Data-Sheet11LR.pdf.

[39] D. Bishoyi and K. Sudhakar, "Modeling and performance simulation of 100 MW PTC based solar thermal power plant in Udaipur India," Case studies in thermal engineering, vol. 10, pp. 216-226, 2017.

[40] Y. Stitou, "MENA_CSP_KIP_Jordan_Workshop," 2017, http://cmimarseille.org/menacspkip/wp-content/uploads/ 2017/08/Youssef_Stitou_MENA_CSP_KIP_Jordan_ Workshop_25_July_2017.pdf.

[41] S. T. Mohammad, H. H. Al-Kayiem, M. K. Assadi, O. Sabir, and A. K. Khlief, "An integrated program of a stand-alone parabolic trough solar thermal power plant: code description and test," Case Studies in Thermal Engineering, vol. 12, pp. 26-37, 2018. 

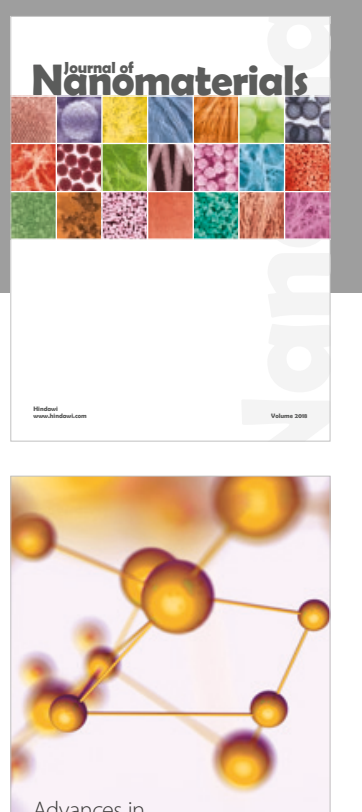

Physical Chemistry
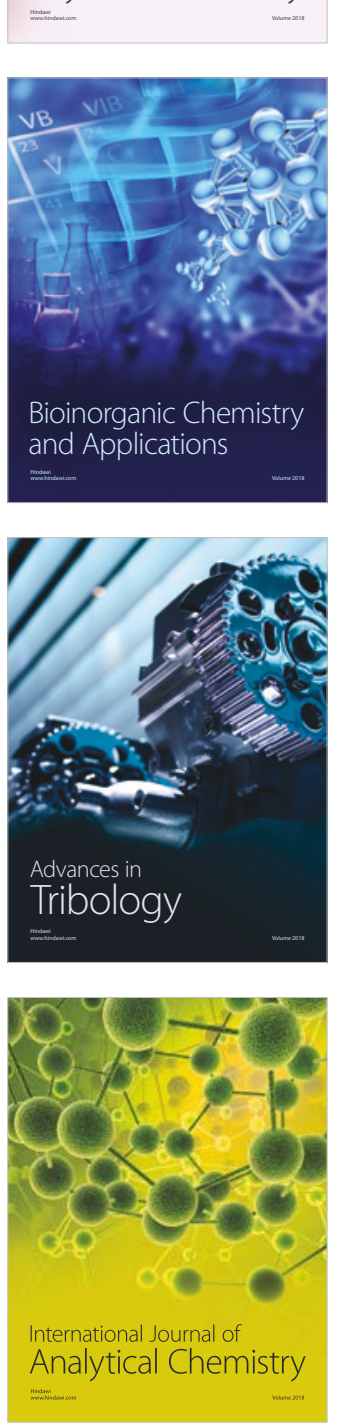

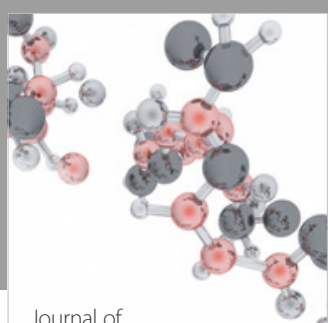

Analytical Methods

in Chemistry

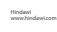

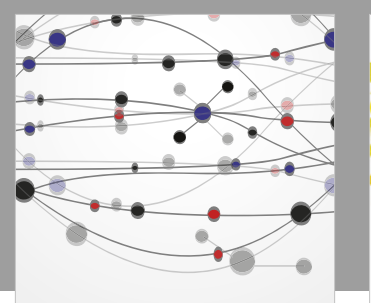

The Scientific World Journal

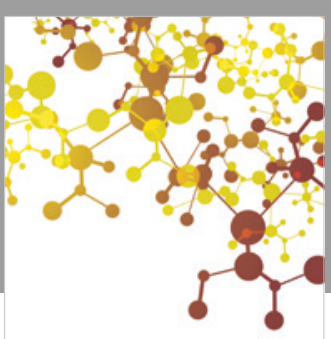

Journal of

Applied Chemistry
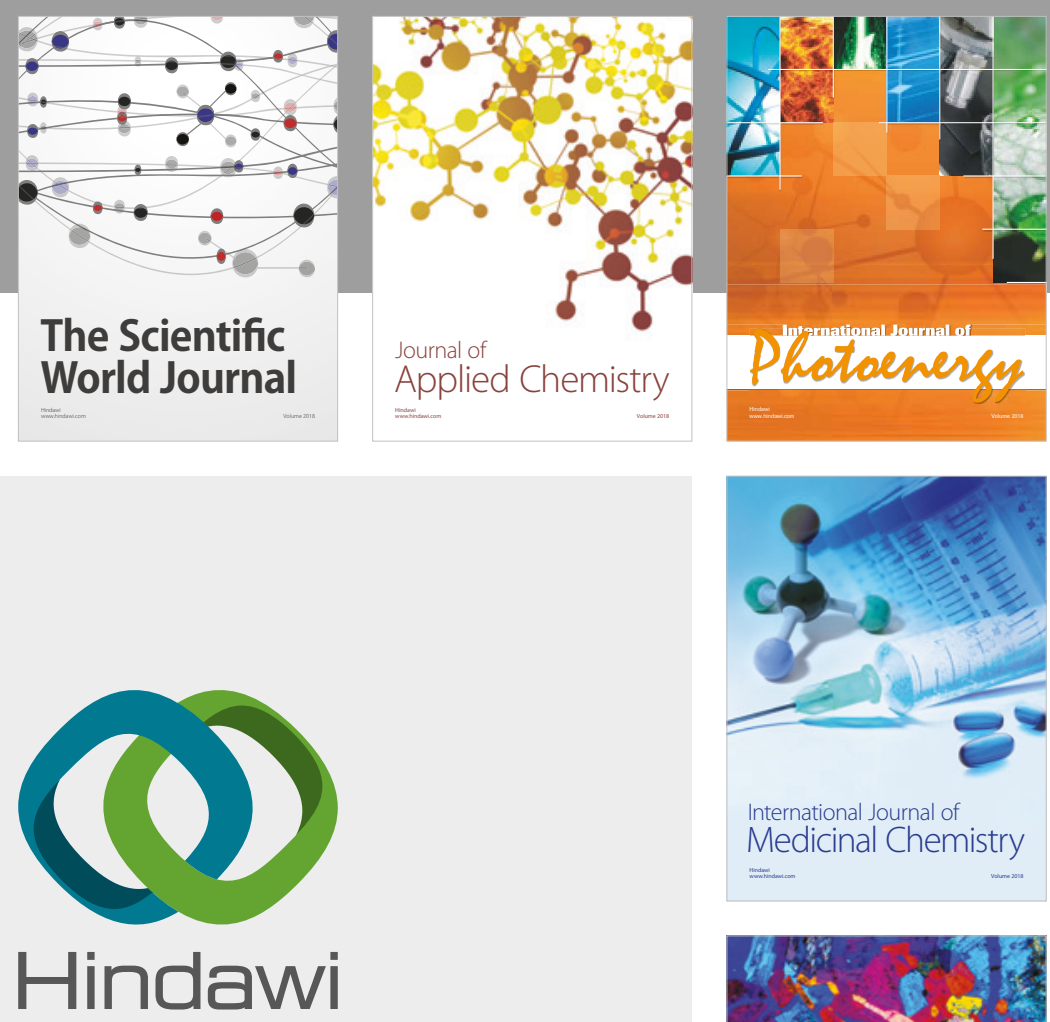

Submit your manuscripts at

www.hindawi.com
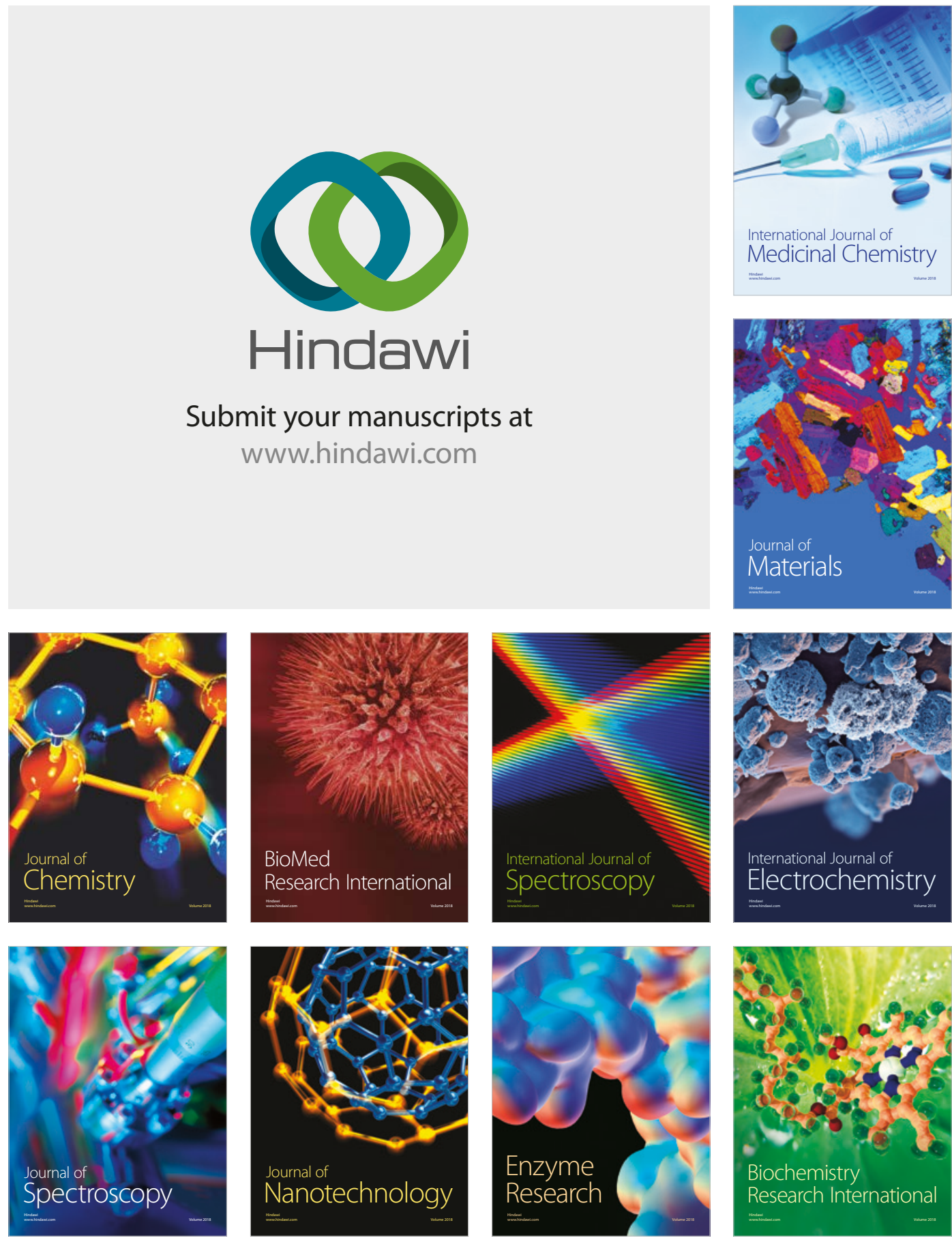
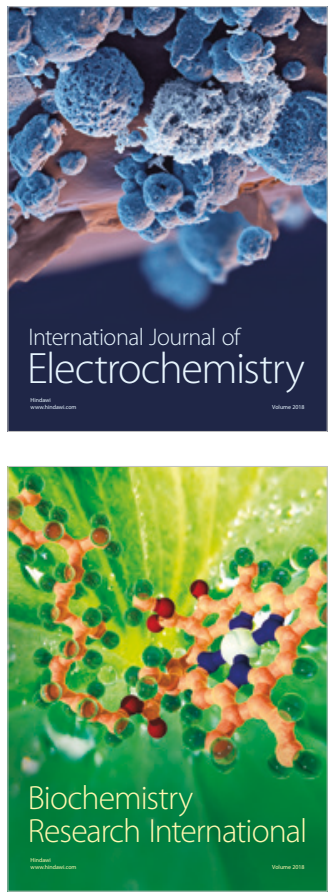